\title{
Evaluation of Input Geological Parameters and Tunnel Strain for Strain-softening Rock Mass Based on GSI
}

\section{Lan Cui}

Chinese Academy of Sciences

\section{Qian Sheng}

Chinese Academy of Sciences

\section{Chen Xu}

China Railway Siyuan Survey and Design Group Co., Ltd

youkou dong ( $\sim$ dongyk@cug.edu.cn )

China University of Geosciences

\section{Research Article}

Keywords: tunnel strain, geological strength parameter, strain-softening effect, regression analysis

Posted Date: November 10th, 2021

DOI: https://doi.org/10.21203/rs.3.rs-1041854/v1

License: (9) This work is licensed under a Creative Commons Attribution 4.0 International License. Read Full License 


\title{
Evaluation of input geological parameters and tunnel strain for strain-softening rock mass based on GSI
}

\author{
Lan Cui ${ }^{\mathrm{b}, \mathrm{c}}$, Qian Sheng ${ }^{\mathrm{b}, \mathrm{c}}$, Chen Xu ${ }^{\mathrm{d}}$, You-kou Dong ${ }^{\mathrm{a}}$
}

\section{Lan Cui}

Assistant Professor

${ }^{\mathrm{b}}$ State Key Laboratory of Geomechanics and Geotechnical Engineering, Institute of Rock and Soil Mechanics, Chinese Academy of Sciences, Wuhan 430071, China

${ }^{\mathrm{c}}$ University of Chinese Academy of Sciences, Beijing 100049, China

Tel: +8613129953337

Email: cuilan@hust.edu.cn

\section{Qian Sheng}

Professor

${ }^{\mathrm{b}}$ State Key Laboratory of Geomechanics and Geotechnical Engineering, Institute of Rock and Soil Mechanics, Chinese Academy of Sciences, Wuhan 430071, China

${ }^{\mathrm{c}}$ University of Chinese Academy of Sciences, Beijing 100049, China

Tel: +8613907125193

Email: qsheng@whrsm.ac.cn

\section{Chen Xu}

Engineer

${ }^{d}$ China Railway Siyuan Survey and Design Group Co., Ltd., Wuhan 430063, China

Tel: +86 18571501912

Email: xc1505@126.com

\section{You-Kou Dong (corresponding author)}

Associate Professor 
a College of Marine Science and Technology, China University of Geosciences, Wuhan 430074,

\section{China}

Tel: +86 13212714650

Email: dongyk@cug.edu.cn 


\section{Abstract}

The regression analysis method is being widely adopted to analyse the tunnel strain, most of which ignore the strain-softening effect of the rock mass and also fail to consider the influence of support pressure, initial stress state, and rock mass strength classification in one fitting equation. This study aims to overcome these deficiencies with a regression model used to estimate the tunnel strain. A group of geological strength indexes (GSI) are configured to quantify the input strength parameters and deformation moduli for the rock mass with a quality ranging from poor to excellent. A specific numerical procedure is developed to calculate the tunnel strain around a circular opening, which is validated by comparison with those using existing methods. A nonlinear regression model is then established to analyse the obtained tunnel strain, combining twelve fitting equations to relate the tunnel strain and the factors including the support pressure, the GSI, the initial stress state, and the critical softening parameter. Particularly, three equations are for the estimation of the critical tunnel strain, the critical support pressure, and the tunnel strain under elastic behaviour, respectively; and the other nine equations are for the tunnel strain with different strain-softening behaviours. The relative significance between the GSI, the initial stress and the support pressure on the tunnel strain is assessed.

Keywords: tunnel strain, geological strength parameter; strain-softening effect; regression analysis. 


\section{Introduction}

The tunnel closure should be predicted appropriately as it is utilised to determine the stability of the rock mass and has been adopted in the engineering practices to guide the preliminary support design. Many analytical and numerical methods were proposed to assess the ground reaction curve with different failure criteria, flow rules, and failure behaviours of the rock mass (Einstein and Schwartz, 1980; Lee and Pietruszczak, 2008; Wang et al., 2010). The solutions reveal the relationship between the tunnel strain and the support pressure, which are efficacious for determining the support type with a particular geological condition. However, many solutions are often too cumbersome for practical applications due to its complicated derivation, equations, and multiple geological parameters. In this aspect, empirical methods seem to be more accessible to the engineering practisers due to their simplicity. Rock mass rating (RMR; Barton, 1987, 2002), geological strength index (GSI; Hoek, 1994), and tunnelling quality index Q (Bieniawski, 1978, 1984, 1989) are the commonly utilised systems to guide the tunnel design by adequately quantifying the strength and deformation properties of the rock mass. Based on previous case back-analysis with assumed rock mass behaviours, the empirical methods often fail to account for the input geological parameters for a specific case. Thus, the strain redistribution and support performance cannot always be well-estimated by the empirical methods.

The regression analysis method has been adopted by many researchers to evaluate the tunnel strain as it takes advantage of the accuracy of the numerical tools 
and the convenience of the empirical schemes (Hoek, 1998; Asef et al, 2000; Sari, 2007; Basarir et al., 2010; Goh and Zhang, 2012; Zhang and Goh, 2015). In the existing studies, great amount of data result was obtained using iterative procedures to analyse the large number of tunnelling cases. Multiple geological parameters for each tunnel case were simplified into a single strength parameter, and the rock mass deformation was quantified artificially as a function of the strength parameter using a nonlinear regression model. Among the studies, the functions enable to obtain the tunnel strain or the plastic zone radius for various tunnel cases with various geological scenarios. However, limitation is obvious due to the difficulty when considering the strain of rock mass showing strain-softening behaviours, which is proved to be a common behaviour in numerous rock tests (Alejano et al., 2010). Also, many studies adopted only one fitting equation in the regression model, failing to consider the support pressure, the initial stress, and the strength classification (such as RMR, GSI, and the compressive strength). As a result, application of analysis results with one fitting equation are limited to particular initial stress or rock mass quality.

In this paper, the index GSI is assigned with a group of values to represent the strength parameters and the deformation moduli for a strain-softening rock mass having various qualities. The tunnel strain around a circular opening under a hydrostatic stress state is obtained through a numerical scheme, which is validated through comparison with the previous studies. A more accurate estimation of the tunnel strain is further derived by iterative numerical procedures with different input geological parameters. Twelve fitting equations are proposed with the regression 
analysis method to correlate the tunnel strain with the support pressure, the GSI, the initial stress state, and the critical softening parameter; In particular, three equations are for the critical tunnel strain, the critical support pressure, and the tunnel strain in the elastic zone, and nine equations are for the tunnel strain in the plastic zone with different strain-softening behaviours.

\section{Problem setup}

\subsection{Assumptions}

Some assumptions are considered prior to the analysis:

(1) A circular opening, with a radius of $R_{0}$, is under a hydrostatic stress field of $\sigma_{0}$ asymmetrically distributed around it; the radial stress $\sigma_{\mathrm{r}}$ and the tangential stress $\sigma \theta$ correspond to the minor and major principal stresses $\sigma_{3}$ and $\sigma_{1}$, respectively;

(2) Plane strain condition is considered as the deformation along the longitudinal direction of the tunnel is virtually uniform;

(3) Material of the rock mass is isotropic, continuous, and initially elastic. Near underground excavations where confinement is reduced, most rock mass exhibits post-peak strength loss, which is called strain-softening property. The rock mass presents strain-softening (SS) behaviour; the elastic-perfectly-plastic (EPP) and elastic-brittle-plastic (EBP) behaviours are also considered, which are taken as special cases of the SS behaviour. The SS, EPP, and EBP behaviours of the rock mass induced by excavation operations are shown in Fig. 1. A support pressure $p_{\mathrm{i}}$ is evenly imposed around the tunnel. $\sigma_{\mathrm{r} 2}$ and $\sigma_{\theta 2}$ represent the radial and tangential stresses at the elasto-plastic boundary, respectively. Within a SS rock mass, $\sigma_{\mathrm{r} 1}$ and 
$\sigma \theta 1$ are the radial and tangential stresses at the plastic softening-residual boundary, respectively. The radii of the plastic softening and residual areas are symbolised as $R_{\mathrm{p}}$ and $R_{\mathrm{r}}$, respectively. For the EPP and EBP rock masses, the radius of plastic area is represented as $R_{\mathrm{p}}$.

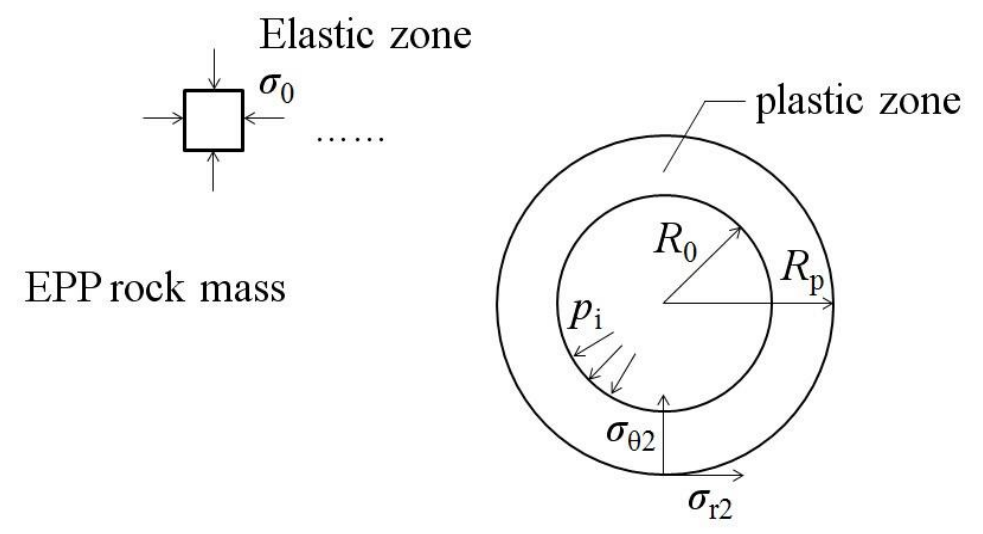

(a)

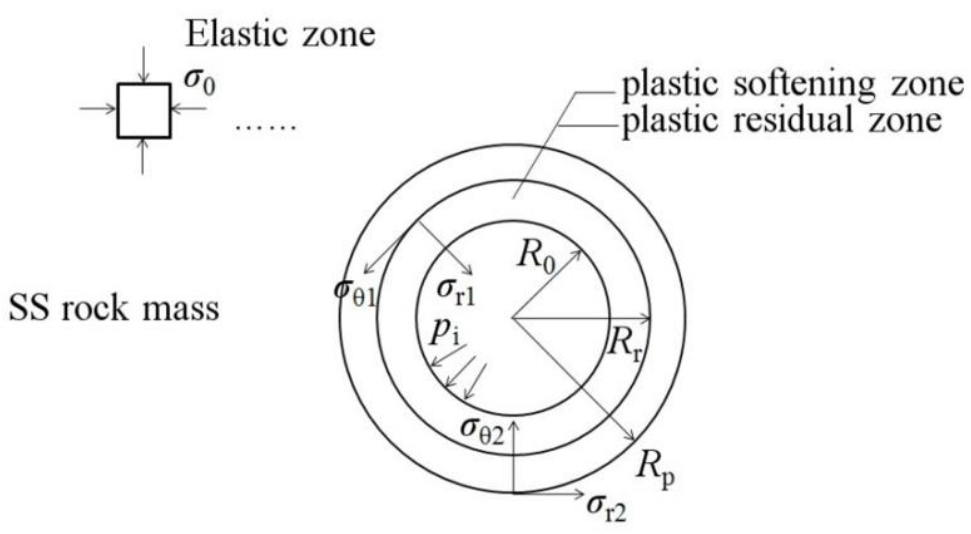

(b)

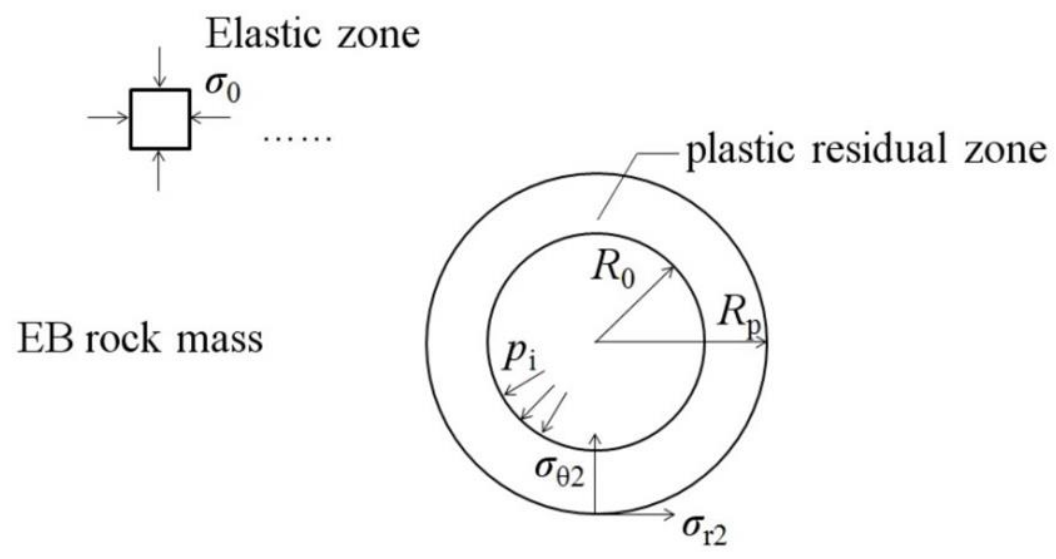

(c) 


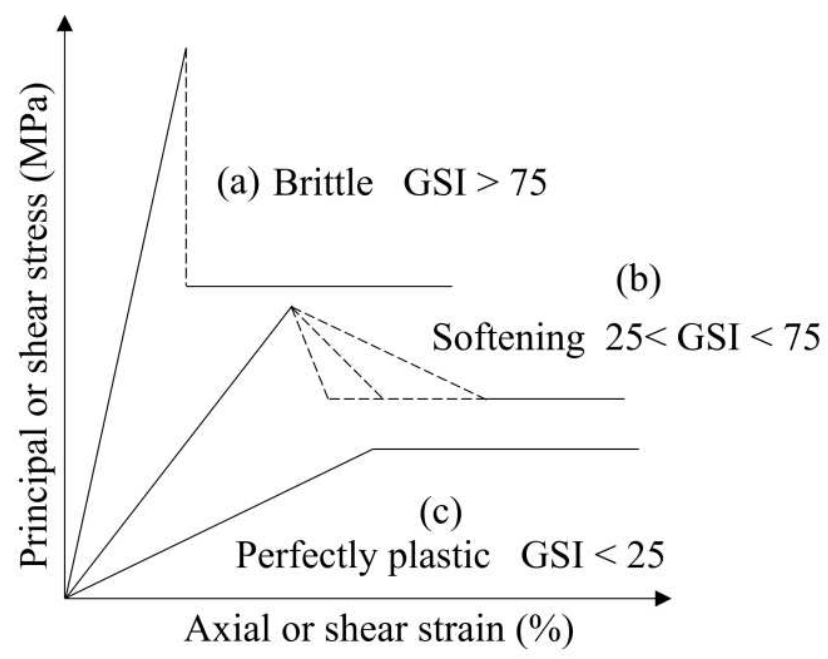

(d)

Fig.1 Schematic graph of excavation problem and stress-strain relationship: (a) for EPP rock mass, (b) for SS rock mass; (c) for EBP rock mass (d) stress-strain relationships

(4) The softening parameter $\eta$ characterises the softening quantity in the rock mass and is calculated as the gap between the tangential and radial plastic strains for the axisymmetric problem:

$$
\eta=\varepsilon_{\theta}^{\text {plas }}-\varepsilon_{\mathrm{r}}^{\text {plas }}
$$

The critical value of $\eta$ is denoted as $\eta^{*}$, which occurs at the moment that the rock mass strength decays to its residual value. Specially, $\eta^{*}$ has values of $\infty$ and 0 for the EPP and EBP rock masses, respectively.

(5) The Mohr-Coulomb failure criterion is considered for the plastic potential function

$$
g\left(\sigma_{\mathrm{r}}, \sigma_{\theta}, \psi\right)=\sigma_{\theta}-\frac{1+\sin \psi}{1-\sin \psi} \sigma_{\mathrm{r}}
$$

where $\psi$ is the dilatancy angle and herein is taken as nil.

(6) The Hoek-Brown (H-B) failure criterion is satisfactory in the quick estimate of the rock mass strength (Hoek et al., 2002):

$$
\sigma_{1}=\sigma_{3}+\sigma_{\mathrm{ci}}\left(m_{\mathrm{b}} \sigma_{3} / \sigma_{\mathrm{ci}}+s\right)^{a}
$$


where $\sigma_{\mathrm{ci}}$ represents the uniaxial compression strength of the intact rock; $m_{\mathrm{b}}, s$ and $a$ are the strength coefficients. Equation (3) can be further re-arranged for the axisymmetric condition

$$
f\left(\sigma_{\mathrm{r}}, \sigma_{\theta}, \eta\right)=\sigma_{\theta}-\sigma_{\mathrm{r}}-\sigma_{\mathrm{ci}}\left(m_{\mathrm{b}} \sigma_{\mathrm{r}} / \sigma_{\mathrm{ci}}+s\right)^{a}
$$

According to the geological observations in the field, Hoek et al. (1994, 1995, 2002) constructed the relation between the strength parameters $\left(m_{\mathrm{b}}, s\right.$ and $\left.a\right)$ and GSI. The empirical equations are listed as follows:

$$
\begin{aligned}
& m_{\mathrm{b}}=m_{\mathrm{i}} \exp \left(\frac{\mathrm{GSI}-100}{28-14 D}\right) \\
& s=\exp \left(\frac{\mathrm{GSI}-100}{9-3 D}\right) \\
& a=\frac{1}{2}+\frac{1}{6}\left(e^{-\mathrm{GSI} / 15}-e^{-20 / 3}\right)
\end{aligned}
$$

where $D$ is a coefficient influenced by the disturbance from blast impact and the stress relaxation. An optimised blasting operation with an accurate drilling control technique are assumed during the tunnel excavation, thereby, the damage to the tunnel wall is negligible and $D$ is regarded as 0 by Hoek (2012). $\quad m_{\mathrm{i}}$ in Eq. (5) characterises the friction between the composition minerals.

\subsection{Strength classification of rock mass}

The strength classification systems, such as the RMR, Q, and GSI, were successfully applied to many tunnel excavations. Various empirical equations by the systems are feasible to characterise the strength and deformation behaviours of the rock mass. Herein, GSI is also incorporated to quantify the rock mass properties. Advantages of the GSI are demonstrated in three aspects: GSI is directly correlated to 
the strength constants in the Hoek-Brown failure criterion (Hoek et al., 2002); GSI can be estimated by RMR and Q systems (Jonny, 1997), thus some strength parameters related to RMR can also be represented by GSI; and the residual strength of the strain-softening rock mass could be calculated from the peak value of GSI based on the equation proposed by Cai et al. (2007).

\subsubsection{Correlation between RMR and GSI}

In Bieniawski (1978) system, RMR equates to GSI:

$$
\mathrm{GSI}=\mathrm{RMR}, \mathrm{RMR}>18
$$

It is noted that Eq. (8) is specialised for the dry condition of the rock mass and thus is not applicable to the weak rock mass with the RMR below 18 .

\subsubsection{Residual value of GSI}

Table $1 \mathrm{GSI}^{\mathrm{p}}$ and GSI ${ }^{\mathrm{r}}$

\begin{tabular}{cccccccccccc}
\hline GSI $^{\mathrm{p}}$ & 25 & 30 & 35 & 40 & 45 & 50 & 55 & 60 & 65 & 70 & 75 \\
\hline GSI $^{\mathrm{r}}$ & 17.9 & 20.1 & 21.9 & 23.4 & 24.6 & 25.6 & 26.3 & 26.9 & 27.2 & 27.4 & 27.5 \\
\hline
\end{tabular}

The guidelines for the GSI was presented in Hoek et al. (1995), which are to characterise the peak strength parameters of the EPP rock mass. Considering the strain-softening effect, Cai et al. (2007) extended the GSI framework to consider the residual strength. Through the in-situ block shear test at a number of real construction sites, the residual value of the GSI, denoted as $\mathrm{GSI}^{\mathrm{r}}$, was expressed with a function of the peak value of GSI, denoted as GSI ${ }^{p}$ :

$$
\mathrm{GSI}^{\mathrm{r}}=\mathrm{GSI}^{\mathrm{p}} \cdot e^{-0.0134 \mathrm{GSI}^{\mathrm{p}}}
$$

Here, GSI ${ }^{\mathrm{p}}$ varies between 25 and 75 with 5 even intervals to consider the rock mass from very poor to excellent qualities. $\mathrm{GSI}^{\mathrm{r}}$ is calculated by substituting $\mathrm{GSI}^{\mathrm{p}}$ into Eq. (9) with values of GSI ${ }^{\mathrm{p}}$ and GSI ${ }^{\mathrm{r}}$ listed in Table 1. 


\section{Geological parameters}

\subsection{Within the plastic softening area}

The parameters $m_{\mathrm{b}}, s$, and $a$ for the SS rock mass can be calculated as (Alonso et al., 2003):

$$
\omega(\eta)=\left\{\begin{array}{l}
\omega^{\mathrm{p}}-\left(\omega^{\mathrm{p}}-\omega^{\mathrm{r}}\right) \frac{\eta}{\eta^{*}}, 0<\eta<\eta^{*} \\
\omega^{\mathrm{r}}, \eta \geq \eta^{*}
\end{array}\right.
$$

where $\omega$ represents any of $m_{\mathrm{b}}, s$, and $a$. The peak and residual values of the strength parameters are denoted with superscripts ' $\mathrm{p}$ ' and ' $\mathrm{r}$ ', respectively, having $m_{\mathrm{b}}$, $, s^{\mathrm{p}}, a^{\mathrm{p}}$ and $m_{\mathrm{b}} \mathrm{r}, s^{\mathrm{r}}, a^{\mathrm{r}}$. The value of $\omega$ decays linearly with the increase in $\eta$ when the rock mass is undergoing plastic softening, while it keeps unchanged with the value of $\eta$ above the critical value $\eta^{*}$. $\omega$ equates to $\omega^{\mathrm{p}}$ within the EPP rock mass and is $\omega^{\mathrm{r}}$ within the plastic area of the EBP rock mass. The deformation modulus $E_{\mathrm{r}}$ and strength parameters, such as $\sigma_{\mathrm{ci}}$ and $m_{\mathrm{i}}$, also need to be determined. A number of compression tests show that $E_{\mathrm{r}}$ deteriorates for the rock mass beyond the peak state (Hudson and Harrison, 2000; Zhang et al., 2012). It is proposed that $\sigma_{\mathrm{ci}}$ wanes from its peak value to the residual during the softening stage since the rock mass quality is weakened, and the variations of $E_{\mathrm{r}}$ and $\sigma_{\mathrm{ci}}$ also obey Eq. (10) (Lee and Pietruszczak, 2008). Therefore, $E_{\mathrm{r}}, \sigma_{\mathrm{ci}}$ and $m_{\mathrm{i}}$ within the plastic softening area are all assumed to obey Eq. (10).

As observed in Eq. (10), the prerequisite for obtaining $E_{\mathrm{r}}, \sigma_{\mathrm{ci}}, m_{\mathrm{i}}, m_{\mathrm{b}}, s$, and $a$ in the softening area is to predict the peak and residual values $\left(E_{\mathrm{r}}^{\mathrm{p}}, E_{\mathrm{r}}^{\mathrm{r}}, \sigma_{\mathrm{ci}}{ }^{\mathrm{p}},{\sigma_{\mathrm{ci}}}^{\mathrm{r}}, m_{\mathrm{i}}^{\mathrm{p}}, m_{\mathrm{i}}^{\mathrm{r}}\right.$, $\left.m_{\mathrm{b}}{ }^{\mathrm{p}}, m_{\mathrm{b}}{ }^{\mathrm{r}}, s^{\mathrm{p}}, s^{\mathrm{r}}, a^{\mathrm{p}}, a^{\mathrm{r}}\right)$. Based on $\mathrm{GSI}^{\mathrm{p}}$ and $\mathrm{GSI}^{\mathrm{r}}$, the derivation of $E_{\mathrm{r}}^{\mathrm{p}}, E_{\mathrm{r}}^{\mathrm{r}}, \sigma_{\mathrm{ci}}{ }^{\mathrm{p}}, \sigma_{\mathrm{ci}}{ }^{\mathrm{r}}, m_{\mathrm{i}}{ }^{\mathrm{p}}$, 
$m_{\mathrm{i}}^{\mathrm{r}}, m_{\mathrm{b}} \mathrm{p}, m_{\mathrm{b}}^{\mathrm{r}}, s^{\mathrm{p}}, s^{\mathrm{r}}, a^{\mathrm{p}}, a^{\mathrm{r}}$ is presented in the following.

\subsection{Within the plastic elastic and plastic residual areas}

\subsubsection{Deformation modulus $E_{r}$}

Table 2 Calculated values of $E_{\mathrm{r}}^{\mathrm{p}}$ and $E_{\mathrm{r}}^{\mathrm{r}}$ by Eqs. (11) to (14)

\begin{tabular}{cccccccccc}
\hline GSI $^{p}$ & Eq.(11) & Eq.(12) & Eq.(13) & Eq.(14) & GSI $^{\mathrm{r}}$ & Eq.(11) & Eq.(12) & Eq.(13) & Eq.(14) \\
\hline 25 & & 2.371 & 1.563 & 1.050 & 17.884 & & 1.574 & 0.572 & 0.953 \\
30 & & 3.162 & 2.700 & 1.645 & 20.069 & & 1.785 & 0.808 & 1.126 \\
35 & & 4.218 & 4.288 & 2.567 & 21.897 & & 1.983 & 1.050 & 1.295 \\
40 & & 5.623 & 6.400 & 3.986 & 23.403 & & 2.163 & 1.282 & 1.452 \\
45 & & 7.499 & 9.113 & 6.138 & 24.623 & 2.320 & 1.493 & 1.592 \\
50 & & 10.000 & 12.500 & 9.341 & 25.585 & 2.453 & 1.675 & 1.712 \\
55 & 10.000 & 13.335 & 16.638 & 13.965 & 26.320 & 2.559 & 1.823 & 1.809 \\
60 & 20.000 & 17.783 & 21.600 & 20.365 & 26.852 & 2.638 & 1.936 & 1.883 \\
65 & 30.000 & 23.714 & 27.463 & 28.719 & 27.205 & & 2.692 & 2.013 & 1.934 \\
70 & 40.000 & 31.623 & 34.300 & 38.828 & 27.399 & & 2.722 & 2.057 & 1.962 \\
75 & 50.000 & 42.170 & 42.188 & 50.000 & 27.453 & & 2.731 & 2.069 & 1.970 \\
\hline
\end{tabular}

Table 3 Estimated values of $E_{\mathrm{r}}^{\mathrm{p}}$ and $E_{\mathrm{r}}^{\mathrm{r}}$

\begin{tabular}{cccc}
\hline $\mathrm{GSI}^{\mathrm{p}}$ & $E_{\mathrm{r}}^{\mathrm{p}}(\mathrm{MPa})$ & $\mathrm{GSI}^{\mathrm{r}}$ & $E_{\mathrm{r}}^{\mathrm{r}}(\mathrm{MPa})$ \\
\hline 75 & 46.089 & 27.453 & 2.037 \\
70 & 36.188 & 27.399 & 2.027 \\
65 & 27.474 & 27.205 & 1.995 \\
60 & 19.937 & 26.852 & 1.938 \\
55 & 13.484 & 26.320 & 1.855 \\
50 & 10.614 & 25.585 & 1.745 \\
45 & 7.583 & 24.623 & 1.610 \\
40 & 5.336 & 23.403 & 1.452 \\
35 & 3.691 & 21.897 & 1.276 \\
30 & 2.502 & 20.069 & 1.089 \\
25 & 1.661 & 17.883 & 0.900 \\
\hline
\end{tabular}

Empirical equations to determine $E_{\mathrm{r}}$ were proposed with GSI and RMR.

Bieniawski (1978):

$$
E_{\mathrm{r}}=2 \mathrm{RMR}-100
$$

Serafim and Pereira (1983):

$$
E_{\mathrm{r}}=10^{(\mathrm{RMR}-10) / 40}
$$


Read et al. (1999):

$$
E_{\mathrm{r}}=0.1\left(\frac{\mathrm{RMR}}{10}\right)^{3}
$$

Simplified Hoek and Diederichs equation (2006):

$$
E_{\mathrm{r}}=100\left(\frac{1-D / 2}{1+e^{((75+25 D-G S I) / 11)}}\right)
$$

With GSI ${ }^{\mathrm{p}}$ and GSI ${ }^{\mathrm{r}}$ listed in Table 1, the calculated $E_{\mathrm{r}}{ }^{\mathrm{p}}$ and $E_{\mathrm{r}}{ }^{\mathrm{r}}$ from Eqs. (11) (14) are shown in Table 2. In Table $3, E_{\mathrm{r}}^{\mathrm{p}}$ and $E_{\mathrm{r}}^{\mathrm{r}}$ can be estimated as the average values from Eqs. (11) - (14).

\subsubsection{Strength constant $m_{i}$}

Table 4 Values of $m_{\mathrm{i}}$ with different GSI: (a) Hoek and Brown (1997); (b) Hoek and Marinos (2000)

(a)

\begin{tabular}{ccccccccc}
\hline GSI & 75 & 50 & 30 & 75 & 75 & 65 & 20 & 24 \\
\hline$m_{\mathrm{i}}$ & 25 & 12 & 8 & 16.3 & 17.7 & 15.6 & 9.6 & 10 \\
\hline
\end{tabular}

\begin{tabular}{ccccc}
\hline GSI & 20 & 5 & 13 & 28 \\
\hline$m_{\mathrm{i}}$ & 8.0 & 2.0 & 5.0 & 11.0 \\
\hline
\end{tabular}

In the previous works, such as Hoek and Brown $(1980,1997)$ and Basarir (2008), $m_{\mathrm{i}}$ was approximated by two methods. One is to determine the classification of $m_{\mathrm{i}}$ from the rock type, such as in Hoek and Brown (1980). The other method is to estimate $m_{\mathrm{i}}$ from the rock mass quality. Although the latter method tends to be subjective, it presents various rock mass qualities that seems to be reasonable (Asef et al., 2000); meanwhile, it enables to establish a direct relationship between $m_{\mathrm{i}}$ and the rock mass strength classification. Therefore, the latter method is utilised in this study to correlate $m_{\mathrm{i}}$ with GSI. The test data of $m_{\mathrm{i}}$ for different GSI by Hoek and Brown (1997) and Hoek and Marinos (2007) is listed in Table 4. The data for 
estimating $m_{\mathrm{i}}$ by GSI can be best-fitted by

$$
m_{\mathrm{i}}=0.7375 \mathrm{GSI}^{0.7586}
$$

The coefficient of determination $R^{2}$ reaches $91.58 \%$, which indicates that the fitting line agrees well with the test results. By Eq. (15), the calculated $m_{\mathrm{i}}^{\mathrm{p}}$ and $m_{\mathrm{i}}^{\mathrm{r}}$ with different $\mathrm{GSI}^{\mathrm{p}}$ and $\mathrm{GSI}^{\mathrm{r}}$ are presented in Table 5.

Table 5 Estimated values of $m_{\mathrm{i}}^{\mathrm{p}}$ and $m_{\mathrm{i}}^{\mathrm{r}}$

\begin{tabular}{cccc}
\hline GSI $^{\mathrm{p}}$ & $m_{\mathrm{i}}^{\mathrm{p}}$ & $\mathrm{GSI}^{\mathrm{r}}$ & $m_{\mathrm{i}}^{\mathrm{r}}$ \\
\hline 75 & 19.507 & 27.453 & 9.101 \\
70 & 18.512 & 27.399 & 9.087 \\
65 & 17.500 & 27.205 & 9.038 \\
60 & 16.469 & 26.852 & 8.949 \\
55 & 15.417 & 26.320 & 8.814 \\
50 & 14.342 & 25.585 & 8.627 \\
45 & 13.240 & 24.623 & 8.380 \\
40 & 12.108 & 23.403 & 8.063 \\
35 & 10.942 & 21.897 & 7.666 \\
30 & 9.734 & 20.069 & 7.176 \\
25 & 8.477 & 17.883 & 6.575 \\
20 & 7.157 & 15.298 & 5.840 \\
\hline
\end{tabular}

Table 6 Estimated values of $m_{\mathrm{b}}{ }^{\mathrm{p}}, s^{\mathrm{p}}, a^{\mathrm{p}}$ and $m_{\mathrm{b}}^{\mathrm{r}}, s^{\mathrm{r}}, a^{\mathrm{r}}$

\begin{tabular}{cccccccc}
\hline $\mathrm{GSI}^{\mathrm{p}}$ & $m_{\mathrm{b}}^{\mathrm{p}}$ & $s^{\mathrm{p}}$ & $a^{\mathrm{p}}$ & $\mathrm{GSI}^{\mathrm{r}}$ & $m_{\mathrm{b}}{ }^{\mathrm{r}}$ & $s^{\mathrm{r}}$ & $a^{\mathrm{r}}$ \\
\hline 75 & 7.988 & 62.177 & 0.501 & 27.453 & 0.682 & 0.316 & 0.527 \\
70 & 6.341 & 35.674 & 0.501 & 27.399 & 0.680 & 0.314 & 0.527 \\
65 & 5.014 & 20.468 & 0.502 & 27.205 & 0.671 & 0.307 & 0.527 \\
60 & 3.947 & 11.744 & 0.503 & 26.852 & 0.656 & 0.295 & 0.528 \\
55 & 3.090 & 6.738 & 0.504 & 26.320 & 0.634 & 0.278 & 0.529 \\
50 & 2.405 & 3.866 & 0.506 & 25.585 & 0.605 & 0.257 & 0.530 \\
45 & 1.857 & 2.218 & 0.508 & 24.623 & 0.568 & 0.230 & 0.532 \\
40 & 1.421 & 1.273 & 0.511 & 23.403 & 0.523 & 0.201 & 0.535 \\
35 & 1.074 & 0.730 & 0.516 & 21.897 & 0.471 & 0.170 & 0.539 \\
30 & 0.799 & 0.419 & 0.522 & 20.069 & 0.413 & 0.139 & 0.544 \\
25 & 0.582 & 0.240 & 0.531 & 17.883 & 0.350 & 0.109 & 0.550 \\
20 & 0.411 & 0.138 & 0.544 & 15.298 & 0.284 & 0.082 & 0.560 \\
\hline
\end{tabular}

\subsubsection{Strength constants $m_{\mathrm{b}}, s$ and $a$}

According to Eqs. (5) to (7), when the disturbance factor $D$ is $0, m_{\mathrm{b}}{ }^{\mathrm{p}}$ and $m_{\mathrm{b}}{ }^{\mathrm{r}}$ can be obtained from GSI ${ }^{\mathrm{p}}, \mathrm{GSI}^{\mathrm{r}}, m_{\mathrm{i}}^{\mathrm{p}}$, and $m_{\mathrm{i}}^{\mathrm{r}}$; and $s^{\mathrm{p}}, s^{\mathrm{r}}, a^{\mathrm{p}}, a^{\mathrm{r}}$ can be calculated from $\mathrm{GSI}^{\mathrm{p}}$ 
and GSIr. The estimated result is listed in Table 6.

\subsubsection{Compressive strength of intact rock $\sigma_{\mathrm{ci}}$}

Here, $\sigma_{\mathrm{ci}}$ by GSI is calculated in three steps.

(1) Estimation of $\sigma_{\mathrm{cm}} / \sigma_{\mathrm{ci}}$

Table 7 Estimated values of $\sigma_{\mathrm{cm}} / \sigma_{\mathrm{ci}}$ proposed by Wilson (1980)

\begin{tabular}{cccccccccc}
\hline GSI & 20 & 30 & 40 & 50 & 60 & 70 & 80 & 90 & 100 \\
\hline$\sigma_{\mathrm{ci}} / \sigma_{\mathrm{cm}}$ & 0.143 & 0.143 & 0.143 & 0.167 & 0.200 & 0.250 & 0.400 & 0.667 & 1.000 \\
\hline
\end{tabular}

Considering different RMR, the reduction factor $\sigma_{\mathrm{cm}} / \sigma_{\mathrm{ci}}$ was proposed by Wilson (1980) to characterise the rock mass strength decreasing from its peak value to the residual. Assuming RMR equals to GSI (see Eq. (8)), the estimated $\sigma_{\mathrm{cm}} / \sigma_{\mathrm{ci}}$ by Wilson (1980) are listed in Table 7. Other fitting equations for $\sigma_{\mathrm{cm}} / \sigma_{\mathrm{ci}}$ in the literature are presented in Eqs. (16) to (22):

Hoek and Brown (1980):

$$
\frac{\sigma_{\mathrm{cm}}}{\sigma_{\mathrm{ci}}}=\sqrt{e^{\left(\frac{\mathrm{RMR}-100}{9}\right)}}
$$

Yudhbir et al. (1983):

$$
\frac{\sigma_{\mathrm{cm}}}{\sigma_{\mathrm{ci}}}=e^{(0.0765 \mathrm{RMR}-7.65)}
$$

Kalamaris and Bieniawski (1995):

$$
\frac{\sigma_{\mathrm{cm}}}{\sigma_{\mathrm{ci}}}=e^{\left(\frac{\mathrm{RMR}-100}{24}\right)}
$$

Sheorey (1997):

$$
\frac{\sigma_{\mathrm{cm}}}{\sigma_{\mathrm{ci}}}=e^{\left(\frac{\mathrm{RMR}-100}{20}\right)}
$$

Ramamurthy (1986):

$$
\frac{\sigma_{\mathrm{cm}}}{\sigma_{\mathrm{ci}}}=e^{\left(\frac{\mathrm{RMR}-100}{18.75}\right)}
$$


Aydan and Dalgic (1998):

$$
\frac{\sigma_{\mathrm{cm}}}{\sigma_{\mathrm{ci}}}=\frac{\mathrm{RMR}}{\mathrm{RMR}+6(100-\mathrm{RMR})}
$$

Hoek (2012):

$$
\frac{\sigma_{\mathrm{cm}}}{\sigma_{\mathrm{ci}}}=0.019 e^{0.05 \mathrm{GSI}}, 5 \leq \mathrm{GSI} \leq 35
$$

The GSI was given values from 5 to 95 with 10 intervals, which is to compute $\sigma_{\mathrm{cm}} / \sigma_{\mathrm{ci}}$ through Eqs. (16) to (22). The otained $\sigma_{\mathrm{cm}} / \sigma_{\mathrm{ci}}$ by Eqs. (16) to (22), by Wilson (1980), and the field data retrieved from realistic construction sites (Aydan and Dalgic, 1998) are plotted in Fig. 2. With the estimated $\sigma_{\mathrm{cm}} / \sigma_{\mathrm{ci}}$, the best-fitting equation is expressed as:

$$
\frac{\sigma_{\mathrm{cm}}}{\sigma_{\mathrm{ci}}}=0.0387+0.00474 e^{\frac{\mathrm{GSI}}{18.9086}}
$$

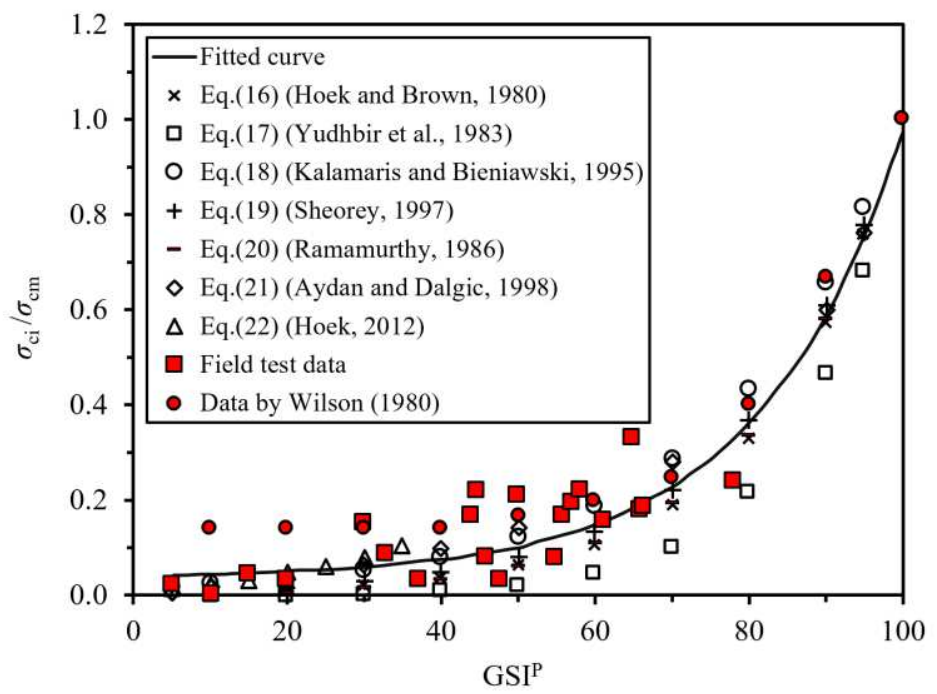

Fig.2 Fitting for $\sigma_{\mathrm{c} i} / \sigma_{\mathrm{cm}}$

The coefficient of determination $R^{2}$ is $93.712 \%$, which indicates the prediction by Eq. (23) is acceptable.

(2) Estimation of $\sigma_{\mathrm{cm}}$ and $\sigma_{\mathrm{ci}}$ 
Trueman (1988) claimed that $\sigma_{\mathrm{cm}}$ can be described as a function of RMR:

$$
\sigma_{\mathrm{cm}}=0.5 e^{0.06 \mathrm{RMR}}
$$

Combing Eqs. (23) and (24), the solution for $\sigma_{\mathrm{ci}}$ is derived as:

$$
\sigma_{\mathrm{ci}}=\frac{0.5 e^{0.06 \mathrm{GSI}}}{0.0387+0.00474 e^{\frac{\mathrm{GSI}}{18.9086}}}
$$

$\sigma_{\mathrm{ci}}{ }^{\mathrm{p}}$ and ${\sigma_{\mathrm{ci}}}^{\mathrm{r}}$ with different values of GSI ${ }^{\mathrm{p}}$ and $\mathrm{GSI}^{\mathrm{r}}$ are calculated by Eq. (25), and the result is presented in Table 8 .

Table 8 Estimated values of ${\sigma_{\mathrm{ci}}}^{\mathrm{p}}$ and ${\sigma_{\mathrm{ci}}}^{\mathrm{r}}$

\begin{tabular}{cccc}
\hline $\mathrm{GSI}^{\mathrm{p}}$ & $\sigma_{\mathrm{ci}}^{\mathrm{p}}(\mathrm{MPa})$ & $\mathrm{GSI}^{\mathrm{r}}$ & $\sigma_{\mathrm{ci}}^{\mathrm{r}}(\mathrm{MPa})$ \\
\hline 75 & 155.762 & 27.453 & 44.044 \\
70 & 144.463 & 27.399 & 43.944 \\
65 & 132.681 & 27.205 & 43.587 \\
60 & 120.465 & 26.852 & 42.945 \\
55 & 107.932 & 26.320 & 41.988 \\
50 & 95.274 & 25.585 & 40.689 \\
45 & 82.749 & 24.623 & 39.028 \\
40 & 70.652 & 23.403 & 36.992 \\
35 & 59.282 & 21.897 & 34.582 \\
30 & 48.894 & 20.069 & 31.812 \\
\hline
\end{tabular}

\section{Numerical procedure}

The closed-form solution of tunnel strain for the EPP and EBP rock masses can be derived by assuming that the strength within the plastic (or plastic residual) area is constant (Sharan, 2005). Since variation of the strength parameters within the plastic softening area is difficult to predict, the strain-softening effect was usually taken into account by using numerical methods (Alonso et al., 2003; Zhang et al., 2012). Here, a numerical procedure is proposed to achieve the tunnel strain, essentially the tangential strain $\varepsilon_{\theta}$, for the SS rock mass.

Within the EPP, SS, and EBP rock masses, the radial stress at the elasto-plastic boundary $\sigma_{\mathrm{r} 2}$ can be calculated with the subsequent equation using the 
Newton-Raphson method:

$$
\sigma_{\mathrm{ci}}^{\mathrm{p}}\left(m_{\mathrm{b}}^{\mathrm{p}} \sigma_{\mathrm{r} 2} / \sigma_{\mathrm{ci}}+s^{\mathrm{p}}\right)^{a^{\mathrm{p}}}+2 \sigma_{\mathrm{r} 2}-2 \sigma_{0}=0
$$

The strain components $\varepsilon_{\theta 2}$ and $\varepsilon_{\mathrm{r} 2}$ at the elasto-plastic boundary are calculated as:

$$
\begin{aligned}
& \varepsilon_{\theta 2}=\frac{(1+\mu)\left(\sigma_{0}-\sigma_{\mathrm{r} 2}\right)}{E_{\mathrm{r}}^{\mathrm{p}}} \\
& \varepsilon_{\mathrm{r} 2}=-\frac{(1+\mu)\left(\sigma_{0}-\sigma_{\mathrm{r} 2}\right)}{E_{\mathrm{r}}^{\mathrm{p}}}
\end{aligned}
$$

where $\mu$ represents the Possion's ratio and is assumed as 0.25 in this study.

It is found that $\sigma_{\mathrm{r} 2}$ and $\varepsilon_{\theta 2}$ are the critical support pressure and critical tunnel strain at the occurrence of the plastic area. Hence, if $p_{\mathrm{i}}>\sigma_{\mathrm{r} 2}, \varepsilon_{\theta}<\varepsilon_{\theta 2}$, the rock mass at the tunnel periphery presents elastic behaviour, and $\varepsilon_{\theta}$ can be calculated as:

$$
\varepsilon_{\theta}=\frac{(1+\mu)\left(\sigma_{0}-p_{\mathrm{i}}\right)}{E_{\mathrm{r}}^{\mathrm{p}}}
$$

If $p_{\mathrm{i}}<\sigma_{\mathrm{r} 2}, \varepsilon_{\theta}>\varepsilon_{\theta 2}$, the plastic softening or the residual area tends to occur around the tunnel, and $\varepsilon_{\theta}$ can be calculated in incremental steps. The finite difference method, developed by Brown et al. (1983) and Lee and Pietruszczak (2008), are used to solve the functions. The plastic area, including the plastic-softening and plastic-residual areas, can be firstly decomposed into a number of concentric annuli $n$ with $r_{(i)}$ and $r_{(i-1)}$ as the inner and outer radii for the $i$ th annulus, $i=1,2, \cdots, n$. At the outer boundary of the plastic area, the initial stress components $\sigma_{\mathrm{r}(0)}$ and $\sigma_{\theta(0)}$ are equal to $\sigma_{\mathrm{r} 2}$ and $\sigma_{\theta 2}$. A fixed increment of the radial stress $\Delta \sigma_{\mathrm{r}}$ is selected for each annulus:

$$
\Delta \sigma_{\mathrm{r}(i)}=\sigma_{\mathrm{r}(i-1)}-\sigma_{\mathrm{r}(i)}=\frac{\sigma_{\mathrm{r} 2}-p_{\mathrm{i}}}{n}
$$

where $\sigma_{\mathrm{r}(i)}$ is the radial stress at $r=r_{(i)}$. 
The ratio $r_{(i)} / r_{(i-1)}$ is (Lee and Pietruszczak, 2008):

$$
\frac{r_{(i)}}{r_{(i-1)}}=\frac{2 H\left(\sigma_{\mathrm{r}(i)}{ }^{\prime}\right)+\Delta \sigma_{\mathrm{r}}}{2 H\left(\sigma_{\mathrm{r}(i)}{ }^{\prime}\right)-\Delta \sigma_{\mathrm{r}}}
$$

where $\sigma_{\mathrm{r}(i)}{ }^{\prime}=\left(\sigma_{\mathrm{r}(i)}+\sigma_{\mathrm{r}(i-1)}\right) / 2$ and $H\left(\sigma_{\mathrm{r}(i)}{ }^{\prime}\right)=\sigma_{\mathrm{ci}(i-1)}\left(m_{(i-1)} \sigma_{\mathrm{r}(i)}{ }^{\prime} / \sigma_{\mathrm{ci}}+s_{(i-1)}\right)^{a_{(i-1)}}$.

Then $\eta_{(i)}$ can be calculated:

$$
\eta_{(i)}=\varepsilon_{\theta(i)}-\varepsilon_{\mathrm{r}(i)}-\Delta \sigma_{\mathrm{r}}-\sigma_{\mathrm{ci}(i-1)}\left(m_{(i-1)} \sigma_{\mathrm{r}(i)} / \sigma_{\mathrm{ci}(i-1)}+s_{(i-1)}\right)^{a_{(i-1)}}
$$

The incremental elastic tangential $\Delta \varepsilon_{\theta(i)}{ }^{\text {elas }}$ and radial strains $\Delta \varepsilon_{\mathrm{r}(i)}^{\text {elas }}$ in the plastic area can be calculated as:

$$
\left\{\begin{array}{l}
\Delta \varepsilon_{\mathrm{r}(i)}^{\text {elas }} \\
\Delta \varepsilon_{\theta(i)}^{\text {elas }}
\end{array}\right\}=\frac{1+\mu}{E_{\mathrm{r}(i)}}\left[\begin{array}{cc}
1-\mu & -\mu \\
-\mu & 1-\mu
\end{array}\right]\left\{\begin{array}{c}
\Delta \sigma_{\mathrm{r}(i)} \\
\Delta \sigma_{\theta(i)}
\end{array}\right\}
$$

Following the non-associated flow rule, $\Delta \varepsilon_{\theta(i)}{ }^{\text {plas }}$ and $\Delta \varepsilon_{\mathrm{r}(i)}{ }^{\text {plas }}$ can be related as:

$$
\Delta \varepsilon_{\mathrm{r}(i)}^{\mathrm{plas}}=-K_{\psi} \Delta \varepsilon_{\theta(i)}^{\mathrm{plas}}
$$

For small strain conditions, the displacement compatibility is:

$$
\varepsilon_{\mathrm{r}(i)}=\frac{\Delta u_{(i)}}{\Delta r_{(i)}}, \varepsilon_{\theta(i)}=\frac{u_{(i)}}{r_{(i)}}
$$

where $u_{(i)}$ represents the radial displacement at $r_{(i)}$.

Combining Eqs. (32) - (34), $\varepsilon_{\mathrm{r}(i)}$ and $\varepsilon_{\theta(i)}$ can be calculated as:

$$
\begin{gathered}
\varepsilon_{\theta(i)}=\frac{u_{(i)}}{r_{(i)}}=\frac{A_{(i-1)}\left(r_{(i)} / r_{(i-1)}-1\right)+u_{(i-1)} / r_{(i-1)}}{r_{(i)} / r_{(i-1)}+K_{\psi}\left(r_{(i)} / r_{(i-1)}-1\right)} \\
\varepsilon_{\mathrm{r}(i)}=\frac{\Delta u_{(i)}}{\Delta r_{(i)}}=-K_{\psi} \varepsilon_{\theta(i)}+\frac{A_{(i-1)}\left(r_{(i)} / r_{(i-1)}-1\right)}{1-r_{(i-1)} / r_{(i)}}
\end{gathered}
$$

where 


$$
A_{(i-1)}=\varepsilon_{\mathrm{r}(i-1)}+K_{\psi} \varepsilon_{\theta(i-1)}+\frac{1+v}{E}\left\{\Delta \sigma_{\mathrm{r}(i)}\left(1-\mu-K_{\psi} \mu\right)+\left[-\Delta \sigma_{\mathrm{r}}+H\left(\sigma_{\mathrm{r}(i)}\right)-H\left(\sigma_{\mathrm{r}(i-1)}\right)\right]\left(K_{\psi}-K_{\psi} \mu-\mu\right)\right\}
$$

The procedure for solving the strain components $\varepsilon_{\mathrm{r}(i)}$ and $\varepsilon_{\theta(i)}$ in the plastic softening and residual areas can be given in Fig. 3.

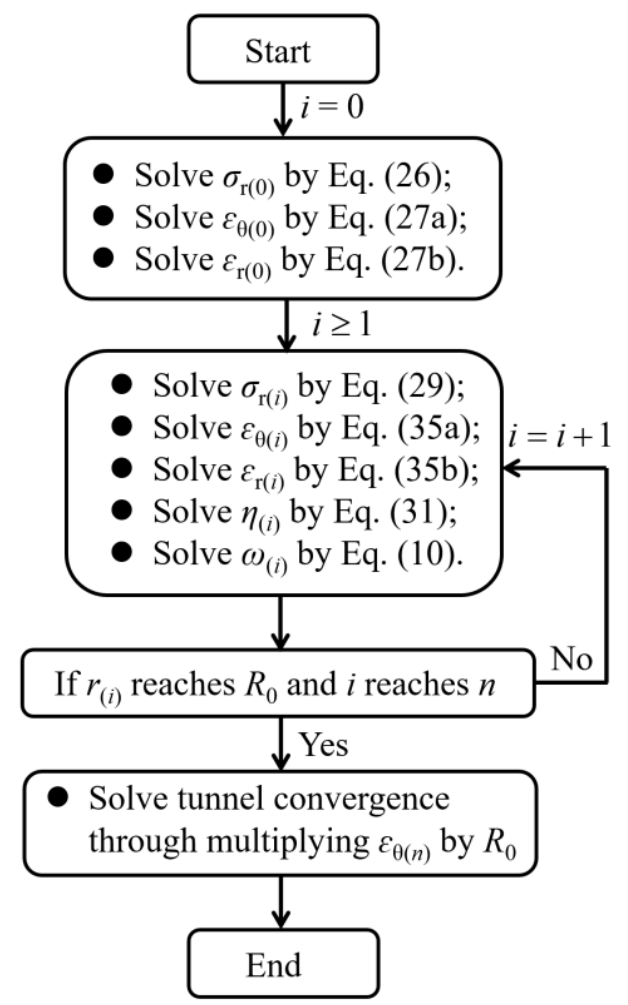

Fig. 3 Numerical procedure to solve tunnel strain

Table 9 Parameters of the tunnel cases for verification

\begin{tabular}{ccccc}
\hline & $\mathrm{C} 1$ & $\mathrm{C} 2$ & $\mathrm{C} 3$ & $\mathrm{C} 4$ \\
\hline$m^{\mathrm{p}}$ & 7.5 & 1.7 & 2 & 0.5 \\
$s^{\mathrm{p}} / 10^{-3}$ & 100 & 3.9 & 4 & 1.0 \\
$m^{\mathrm{r}}$ & 1 & 1 & 0.6 & 0.1 \\
$s^{\mathrm{r}} / 10^{-3}$ & 10 & 0 & 2 & 0.5 \\
$K_{\psi}^{\mathrm{p}}$ & - & - & 1.698 & 1.698 \\
$K_{\psi}^{\mathrm{r}}$ & - & - & 1.191 & 1.191 \\
$\eta^{*} / 10^{-3}$ & - & - & 10 & 12.5 \\
$E_{\mathrm{r}} / \mathrm{GPa}$ & 40 & 5.5 & 5.7 & 1.38 \\
$p_{i} / \mathrm{MPa}$ & 0 & 5 & - & - \\
$\mu$ & 0.2 & 0.25 & 0.25 & 0.25 \\
$R_{0} / \mathrm{m}$ & 4 & 5 & 3 & 3 \\
$\sigma_{\mathrm{ci}}^{\mathrm{p}} / \mathrm{MPa}$ & 300 & 30 & 30 & 27.5 \\
$\sigma_{\mathrm{ci}}^{\mathrm{r}} / \mathrm{MPa}$ & 300 & 30 & 25 & 27.5 \\
$\sigma_{0} / \mathrm{MPa}$ & 108 & 30 & 15 & 3.31 \\
\hline
\end{tabular}

\section{Verification}


The strength parameters for a group of tunnel excavation cases are used to verify the proposed numerical procedure (Table 9). Figure 4 demonstrates the distribution of the normalised radial displacement predicted by the numerical procedure and a closed-form method for the EPP and EBP rock masses, which show good agreement with each other. Comparison of the Ground Reaction Curves for the SS rock mass obtained from the numerical procedure and a multiple-step brittle-plastic method (Wang et al., 2010) are presented in Fig. 5, also showing good convergence. Therefore, the numerical procedure proposed in this study is sufficiently reliable in predicting the tunnel strain for the EPP, EBP, and SS rock masses.

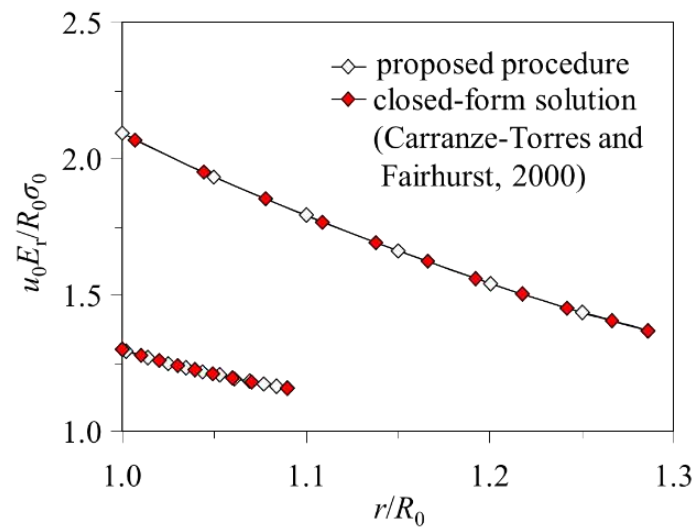

(a)

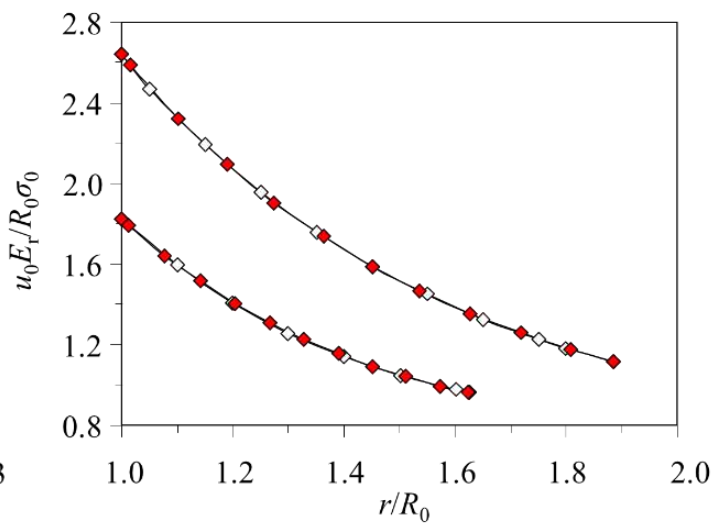

(b)

Fig. 4 Variations of dimensionless displacement $u_{0} E_{\mathrm{r}} / R_{0} \sigma_{0}$ versus dimensionless radial distance $r / R_{0}$ (a) case $\mathrm{C} 1$ (b) case $\mathrm{C} 2$.

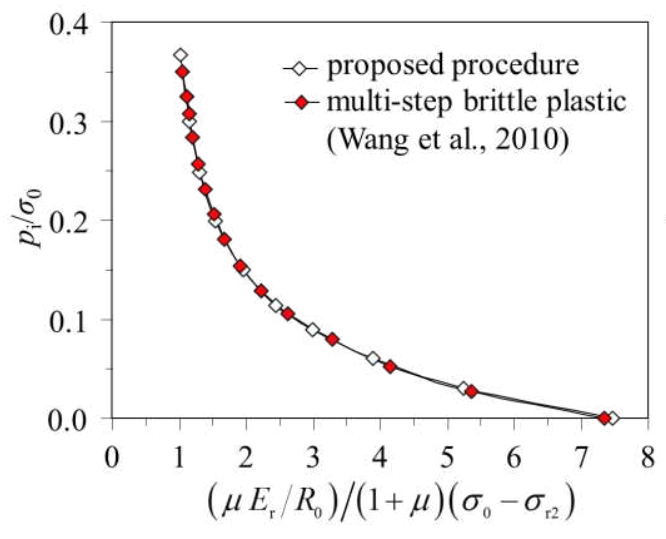

(a)

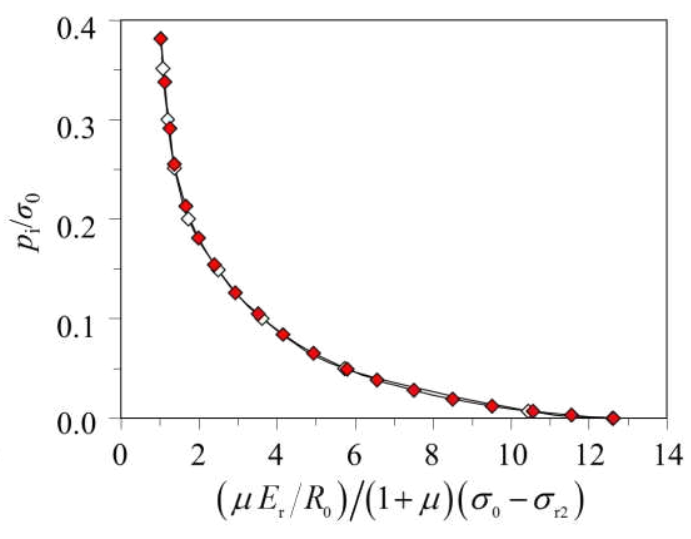

(b)

Fig. 5 Ground Reaction Curves (a) case C3 (b) case C4. 
In some existing studies, efforts were given to calculate the tunnel strain $\varepsilon_{\theta}$ for the EPP rock mass with a wide range of qualities (Hoek, 1998; Asef et al, 2000; Sari, 2007; Basarir, 2008). Particularly, Hoek (1998) proposed an empirical equation for the weak rock mass, i.e. $5<\mathrm{GSI}<35$

$$
\varepsilon_{\theta}=\left(0.002-0.0025 \frac{p_{\mathrm{i}}}{\sigma_{0}}\right){\frac{\sigma_{\mathrm{cm}}}{\sigma_{0}}}^{\left(2.4 \frac{p_{\mathrm{i}}}{\sigma_{0}}-2\right)}
$$

Basarir (2008) established a regression model with $20<\mathrm{RMR}<90$ :

$$
u_{0}(\mathrm{~mm})=\left\{\begin{array}{l}
24711 \times 0.43^{p_{\mathrm{i}}} \times \mathrm{RMR}^{-2.42}, \sigma_{0}=2.7 \mathrm{MPa} \\
157513 \times 0.59^{p_{\mathrm{i}}} \times \mathrm{RMR}^{-2.71}, \sigma_{0}=5.4 \mathrm{MPa} \\
696395 \times 0.65^{p_{\mathrm{i}}} \times \mathrm{RMR}^{-2.99}, \sigma_{0}=8.1 \mathrm{MPa} \\
3973329 \times 0.66^{p_{\mathrm{i}}} \times \mathrm{RMR}^{-3.37}, \sigma_{0}=10.8 \mathrm{MPa} \\
18531047 \times 0.67^{p_{\mathrm{i}}} \times \mathrm{RMR}^{-3.72}, \sigma_{0}=13.5 \mathrm{MPa}
\end{array}\right.
$$

With the input geological parameters obtained from Eq. (37), the value of $\varepsilon_{\theta}$ predicted by the proposed procedures in this study can be compared with that by Eqs. (36) and (37). Then the rationality of the input geological parameters $\left(E_{\mathrm{r}}^{\mathrm{p}}, E_{\mathrm{r}}^{\mathrm{r}}, \sigma_{\mathrm{ci}}{ }^{\mathrm{p}}, \sigma_{\mathrm{ci}}{ }^{\mathrm{r}}, m_{\mathrm{i}}{ }^{\mathrm{p}}\right.$, $m_{\mathrm{i}}^{\mathrm{r}}, m_{\mathrm{b}}{ }^{\mathrm{p}}, m_{\mathrm{b}}{ }^{\mathrm{r}}, s^{\mathrm{p}}, s^{\mathrm{r}}, a^{\mathrm{p}}$, and $\left.a^{\mathrm{r}}\right)$ in this study can be validated.

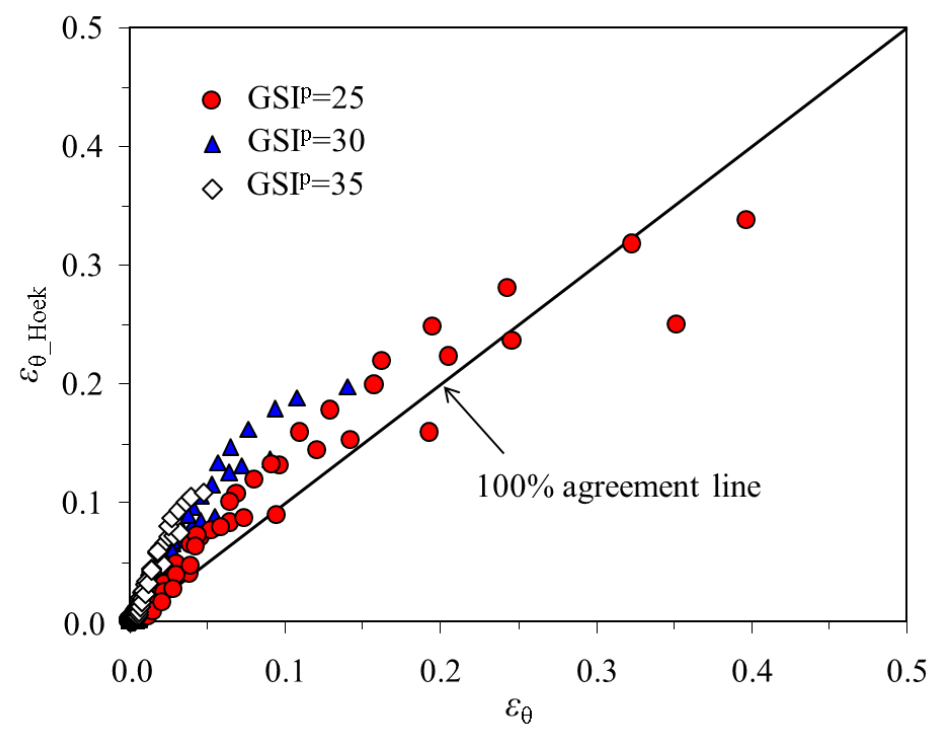

Fig. 6 Comparison between $\varepsilon_{\theta}$ and $\varepsilon_{\theta_{-} \text {Hoek }}$ 
It is mentioned that GSI in Eq. (36) and RMR in Eq. (37) correspond to GSI ${ }^{\mathrm{p}}$ in this study. As GSI in Eq. (36) is between 5 and 35, GSI is selected as 25, 30 and 35. The related geological parameters $\left(E_{\mathrm{r}}^{\mathrm{p}}, \sigma_{\mathrm{ci}}^{\mathrm{p}}, m_{\mathrm{b}}{ }^{\mathrm{p}}, s_{\mathrm{b}}{ }^{\mathrm{p}}, a^{\mathrm{p}}\right)$ for $\mathrm{GSI}^{\mathrm{p}}$ are 25,30 and 35 can be referred to Tables 3, 6 and 8. As the rock mass quality by Hoek (1998) (see Eq. (36)) is represented by $\sigma_{\mathrm{cm}}, \mathrm{GSI}^{\mathrm{p}}$ should be converted to $\sigma_{\mathrm{cm}}$ by Eq. (24). $\sigma_{0}$ varies between 5 and $30 \mathrm{MPa}$ with intervals of $5 \mathrm{MPa}$ for each GSI, and $p_{\mathrm{i}}$ rises gradually from 0 to $\sigma_{0}$. Figure 6 shows the comparison of $\varepsilon_{\theta}$ predicted by the numerical procedure and the counterpart by Hoek (1998). The coefficient of determination $R^{2}$ is $81.1 \%$, which indicates that $\varepsilon_{\theta}$ is basically in agreement with $\varepsilon_{\theta}$ _Hoek. The scattered points are mostly beyond the agreement line, which implies that $\varepsilon_{\theta} \_$Hoek is higher than $\varepsilon_{\theta}$, especially for higher $\mathrm{GSI}^{\mathrm{p}}$ with small tunnel strain. This can be attributed to different solutions of $\sigma_{\mathrm{cm}} / \sigma_{\mathrm{ci}}$ by the two methods. Specifically, $\sigma_{\mathrm{cm}} / \sigma_{\mathrm{ci}}$ is calculated by Eq. (23) in this analysis, whereas by the following equation in Hoek's study (1998):

$$
\frac{\sigma_{\mathrm{cm}}}{\sigma_{\mathrm{ci}}}=0.019 \cdot e^{0.05 \mathrm{GSI}^{\mathrm{p}}}
$$

Given GSI ${ }^{p}$ is 35,30 , and $25, \sigma_{\text {ci }}$ will be $59.28,48.89$, and $39.67 \mathrm{MPa}$ by Eq. (23), and is $37.34 \mathrm{MPa}, 35.52 \mathrm{MPa}$ and $33.79 \mathrm{MPa}$ by Eq. (38). As $\sigma_{\mathrm{ci}}$ by Eq. (38) is fairly lower than that by Eq. (23), $\varepsilon_{\theta} \_$Hoek by Hoek (1998) tends to be greater.

To explain in detail, Eq. (23) for solving $\sigma_{\mathrm{cm}} / \sigma_{\mathrm{ci}}$ within the proposed numerical procedure is replaced with Eq. (38). Then, $\varepsilon_{\theta}$ is obtained by the adjusted $\sigma_{\mathrm{cm}} / \sigma_{\mathrm{ci}}$. Comparison between $\varepsilon_{\theta_{-} H \text { Hoek }}$ and the modified $\varepsilon_{\theta}$ is presented in Fig. 7. The coefficient of determination $R^{2}$ becomes about $92.1 \%$, which means that better 
agreement is reached when $\sigma_{\mathrm{cm}} / \sigma_{\mathrm{ci}}$ is calculated by Eq. (38). Accordingly, disparity of $\varepsilon_{\theta}$ between the two methods becomes greater while $\sigma_{\mathrm{cm}} / \sigma_{\mathrm{ci}}$ is obtained by Eq. (23). However, Equation (38) is only applicable to the rock mass from extremely poor to fair poor (GSI $=5 \sim 35$ ), while Eq. (23) considers a wider range of qualities. Hence, Eq. (23) is still utilised here, and the comparison with Hoek's study (1998) indicates the input geological parameters for the weak rock mass are acceptable.

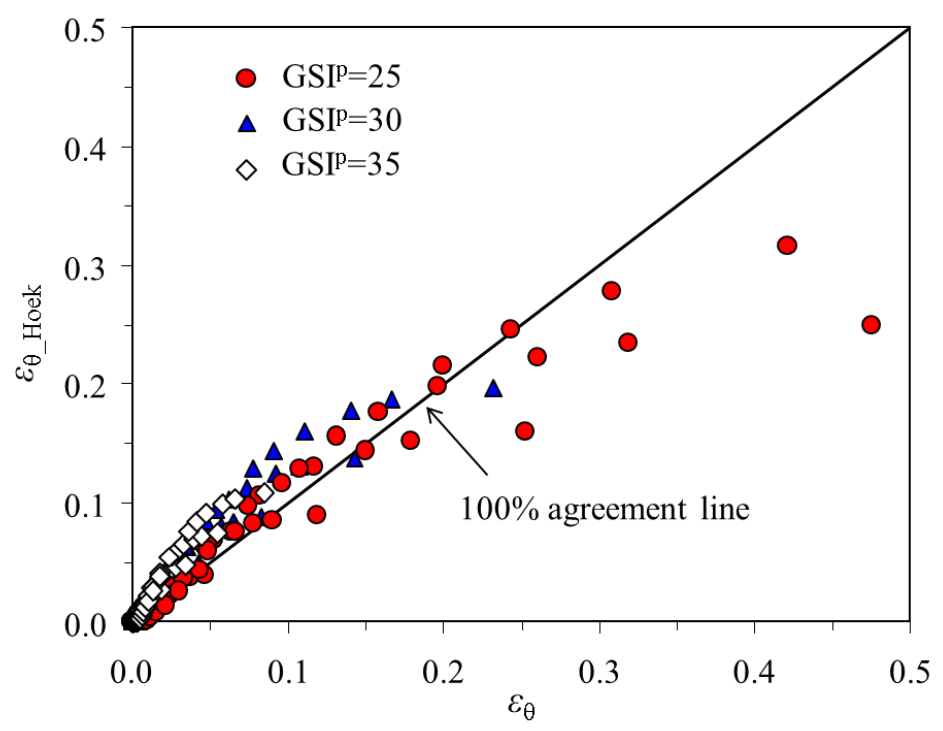

Fig.7 Comparison between adjusted $\varepsilon_{\theta}$ and $\varepsilon_{\theta_{-} \text {Hoek }}$

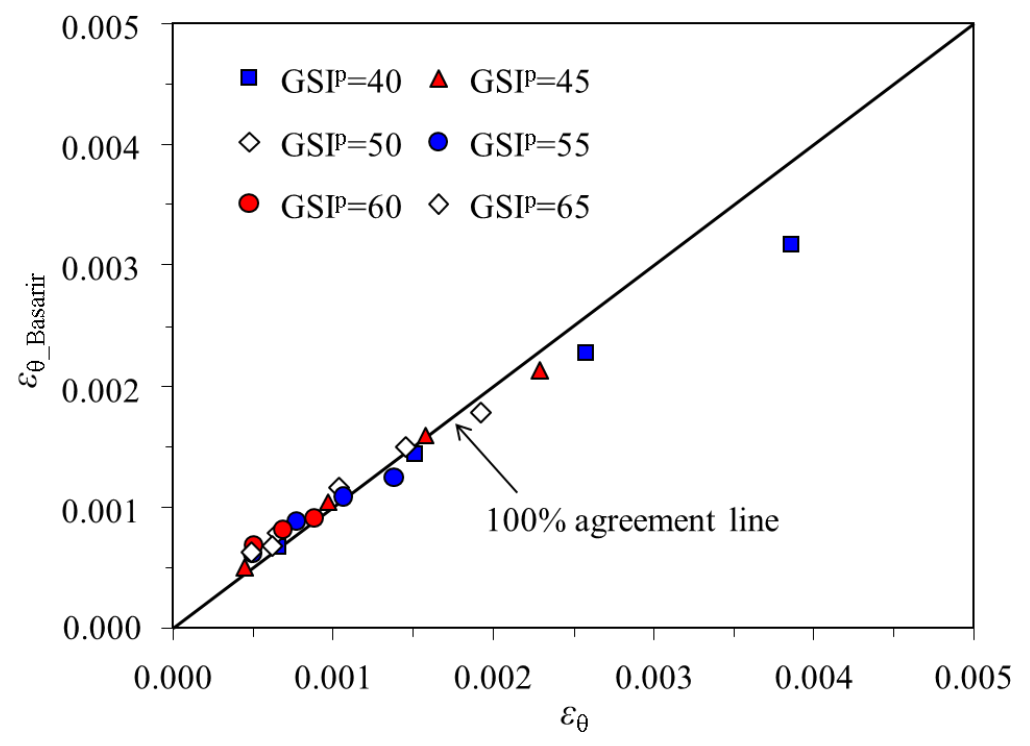

Fig.8 Comparison between $\varepsilon_{\theta}$ and $\varepsilon_{\theta_{-} \text {Basarir }}$

Then GSI ${ }^{p}$ was varied between 40 and 65 with 5 intervals to compare the 
proposed method with that by Basarir (2008). For each GSI value, $\sigma_{0}$ ranges from 2.7 to $13.5 \mathrm{MPa}, p_{\mathrm{i}}$ is 0 and $R_{0}$ is $5 \mathrm{~m}$. By Basarir (2008), $\varepsilon_{\theta_{-}}$Basarir is obtained by dividing $u_{0}$ by $R_{0}$. The comparison of $\varepsilon_{\theta}$ obtained from the numerical procedure and $\varepsilon_{\theta} \_$basarir by the scheme in Basarir (2008) shows good agreement with the coefficient of determination $R^{2}$ up to $90.8 \%$ (see Fig. 8 ).

\section{Regression model for tunnel strain}

The strain $\varepsilon_{\theta}$ can be fitted as a function of $\mathrm{GSI}^{\mathrm{p}}, \sigma_{0}$ and $p_{\mathrm{i}} / \sigma_{0}$ by a nonlinear regression method. The equations for $\varepsilon_{\theta}$ in the plastic and elastic areas differ from each other:

$$
\begin{aligned}
& \varepsilon_{\theta}=f_{1}\left(\mathrm{GSI}^{\mathrm{p}}, \sigma_{0}, p_{\mathrm{i}} / \sigma_{0}\right), \varepsilon_{\theta}>\varepsilon_{\theta 2}, p_{\mathrm{i}}<\sigma_{\mathrm{r} 2}, \text { plastic area } \\
& \varepsilon_{\theta}=f_{2}\left(\mathrm{GSI}^{\mathrm{p}}, \sigma_{0}, p_{\mathrm{i}} / \sigma_{0}\right), \varepsilon_{\theta} \leq \varepsilon_{\theta 2}, p_{\mathrm{i}} \geq \sigma_{\mathrm{r} 2}, \text { elastic area }
\end{aligned}
$$

In Eq. (39), the critical strain $\varepsilon_{\theta 2}$ and the critical support pressure $\sigma_{\mathrm{r} 2}$ need to be determined prior to solving $\varepsilon_{\theta}$. Combining Eqs. (26) and (27a), fitting equations for $\sigma_{\mathrm{r} 2}$ and $\varepsilon_{\theta 2}$ can be written as:

$$
\begin{gathered}
\sigma_{\mathrm{r} 2}=f_{3}\left(\mathrm{GSI}^{\mathrm{p}}, \sigma_{0}\right) \\
\varepsilon_{\theta 2}=f_{4}\left(\mathrm{GSI}^{\mathrm{p}}, \sigma_{0}\right)
\end{gathered}
$$

The Taylor series polynomial regression (PR) can be adopted to solve $f_{1}, f_{3}$ and $f_{4}$.

Particularly for $f_{1}$, a nonlinear function can be constructed as:

$$
\begin{aligned}
& y=\exp \left(a_{1}+b_{1} x_{1}+b_{2} x_{2}+b_{3} x_{3}+c_{1} x_{1}^{2}+c_{2} x_{2}{ }^{2}+c_{3} x_{3}{ }^{2}+c_{4} x_{1} x_{2}+c_{5} x_{3} x_{2}+c_{6} x_{3} x_{1}\right. \\
& +d_{1} x_{3}^{2} x_{2}+d_{2} x_{3}^{2} x_{1}+d_{3} x_{3} x_{1}^{2}+d_{4} x_{3} x_{2}^{2}+d_{5} x_{1} x_{2} x_{3}+d_{6} x_{2}^{3}+d_{7} x_{1}^{3} \\
& +e_{1} x_{1}^{2} x_{2}^{2}+e_{2} x_{2}^{2} x_{3}^{2}+e_{3} x_{3}^{2} x_{1} x_{2}+e_{4} x_{3} x_{1}^{3}+e_{5} x_{3} x_{2}^{3} \\
& \left.+f_{1} x_{1}^{3} x_{3}^{2}+f_{2} x_{2}^{3} x_{3}^{2}\right)
\end{aligned}
$$

For $f_{3}$ and $f_{4}$, the variable $y\left(\varepsilon_{\theta 2}\right.$ or $\left.\sigma_{\mathrm{r} 2}\right)$ depends on $x_{1}\left(\mathrm{GSI}^{\mathrm{p}}\right)$ and $x_{2}\left(\sigma_{0}\right)$, as: 


$$
y=a_{1}+b_{1} x_{1}+b_{2} x_{2}+c_{1} x_{1}^{2}+c_{2} x_{2}^{2}+c_{3} x_{1} x_{2}+d_{1} x_{1}^{3}+d_{2} x_{2}^{3}+d_{3} x_{1} x_{2}^{2}+d_{4} x_{2} x_{1}^{2}
$$

As for $f_{2}$, the relation between the variable $y\left(\varepsilon_{\theta}\right)$ and the independent variables $x_{1}$ $\left(\mathrm{GSI}^{\mathrm{p}}\right), x_{2}\left(\sigma_{0}\right)$, and $x_{3}\left(p_{\mathrm{i}} / \sigma_{0}\right)$ can be derived from Eq. (28) as:

$$
y=\frac{x_{2}(1+\mu)\left(1-x_{3}\right)}{a_{1} x_{1}^{3}+b_{1} x_{1}^{2}+c_{1} x_{1}+d_{1}}
$$

Table 10 Critical plastic softening parameter $\eta^{*}$

\begin{tabular}{cccccccccc}
\hline Case & A1 & A2 & A3 & A4 & A5 & A6 & A7 & A8 & A9 \\
\hline$\eta^{*}$ & 0 & 0.005 & 0.01 & 0.025 & 0.05 & 0.1 & 0.5 & 1 & $\infty$ \\
\hline
\end{tabular}

Table 11 Coefficients in $f_{4}, f_{3}$, and $f_{2}$

\begin{tabular}{lccrrr}
\hline & $f_{4}$ & \multicolumn{3}{c}{$f_{3}$} \\
\hline$a_{1}\left(10^{-5}\right)$ & 41.3845 & $a_{1}$ & -0.28326 & $a_{1}$ & 0.000248 \\
$b_{1}\left(10^{-5}\right)$ & 2.65088 & $b_{1}$ & 0.0335 & $b_{1}$ & -0.01574 \\
$b_{2}\left(10^{-5}\right)$ & 1.14699 & $b_{2}$ & 0.90003 & $c_{1}$ & 0.44914 \\
$c_{1}\left(10^{-5}\right)$ & 0.055412 & $c_{1}$ & -0.00191 & $d_{1}$ & -3.54494 \\
$c_{2}\left(10^{-5}\right)$ & 0.033112 & $c_{2}$ & 0.00918 & & \\
$c_{3}\left(10^{-5}\right)$ & 0.035873 & $c_{3}$ & -0.01945 & & \\
$d_{1}\left(10^{-5}\right)$ & 0.000383 & $d_{1}\left(10^{-5}\right)$ & 2.45031 & & \\
$d_{2}\left(10^{-5}\right)$ & 0.000439 & $d_{2}\left(10^{-5}\right)$ & -7.66756 & & \\
$d_{3}\left(10^{-5}\right)$ & 0.000418 & $d_{3}\left(10^{-5}\right)$ & 1.3373 & & \\
$d_{4}\left(10^{-5}\right)$ & 0.000402 & $d_{4}\left(10^{-5}\right)$ & 5.47132 & & \\
\hline
\end{tabular}

To obtain the coefficients in Eqs. (41) to (43), $\varepsilon_{\theta}$ for a large number of tunnelling cases are calculated by the proposed iterative procedure. The input geological parameters (GSI $, \mathrm{GSI}^{\mathrm{r}}, E_{\mathrm{r}}^{\mathrm{p}}, E_{\mathrm{r}}^{\mathrm{r}}, \sigma_{\mathrm{ci}}{ }^{\mathrm{p}}, \sigma_{\mathrm{ci}}{ }^{\mathrm{r}}, m_{\mathrm{b}}{ }^{\mathrm{p}}, m_{\mathrm{b}}{ }^{\mathrm{r}}, s^{\mathrm{p}}, s^{\mathrm{r}}, a^{\mathrm{p}}$, and $\left.a^{\mathrm{r}}\right)$ for the calculation are given in Tables $1,3,6$, and 8 . Nine values for $\eta^{*}$ within cases A1 to A9 are listed in Table 10. $\sigma_{0}$ varies from 5 to $50 \mathrm{MPa}$ with intervals of $5 \mathrm{MPa} . p_{\mathrm{i}} / \sigma_{0}$ ranges from 0 to $1 \mathrm{MPa}$ and 10 to 20 values are selected for different combination of $p_{\mathrm{i}}$ and $\sigma_{\mathrm{r} 2} . f_{2}$, $f_{3}$ and $f_{4}$ are merely correlated to the peak geological parameters in the elastic zone. The regression model is composed of twelve equations: three equations are for $f_{2}, f_{3}$ and $f_{4}$, and nine equations are for $f_{1}$. Then the coefficients can be determined with the Levenberg Marquardt iteration algorithm (see Tables 11 and 12), which is 
validated through the analysis of variance ANOVA. The predictions with the twelve equations match well with those by the numerical procedure.

Table 12 Coefficients in $f_{1}$ : (a) when $\eta^{*}=\infty, 1,0.5,0.1,0.05$; (b) when $\eta^{*}=0.025,0.01,0.005,0$ (a)

\begin{tabular}{cccccc}
\hline$\eta^{*}$ & $\infty$ & 1 & 0.5 & 0.1 & 0.05 \\
\hline$a_{1}$ & 0.35376 & -0.76117 & -0.59639 & 1.07615 & 3.25504 \\
$b_{1}$ & -0.3222 & -0.24708 & -0.2542 & -0.40415 & -0.56165 \\
$b_{2}$ & -16.0268 & -16.13951 & -16.52177 & -16.44784 & -19.45774 \\
$b_{3}$ & 0.32436 & 0.41005 & 0.41672 & 0.51739 & 0.51157 \\
$c_{1}$ & 0.00398 & 0.00236 & 0.00245 & 0.00616 & 0.00957 \\
$c_{2}$ & 19.40741 & 21.77008 & 22.37404 & 21.44441 & 27.17204 \\
$c_{3}$ & -0.00244 & -0.00174 & -0.00116 & -0.00302 & -0.00495 \\
$c_{4}$ & 0.33585 & 0.34546 & 0.35874 & 0.38257 & 0.45868 \\
$c_{5}$ & -0.07687 & -0.24695 & -0.28771 & -0.70555 & -0.82704 \\
$c_{6}$ & -0.00562 & -0.01094 & -0.01172 & -0.01172 & -0.00666 \\
$d_{1}$ & -0.00053963 & -0.00182 & -0.00243 & 0.00431 & 0.00745 \\
$d_{2}\left(10^{-5}\right)$ & 2.24655 & 0.727777 & -0.812592 & 4.86805 & 10.3186 \\
$d_{3}\left(10^{-5}\right)$ & 4.92234 & 15.3397 & 17.6538 & 8.01328 & -8.19722 \\
$d_{4}$ & -0.01428 & 0.27111 & 0.39644 & 0.82708 & 0.86071 \\
$d_{5}$ & -0.00601 & -0.00268 & -0.00253 & 0.00231 & 0.00268 \\
$d_{6}$ & -15.49541 & -18.03127 & -18.68734 & -19.15351 & -25.09435 \\
$d_{7}\left(10^{-5}\right)$ & -1.72534 & -0.595086 & -0.637556 & -3.37496 & -5.68299 \\
$e_{1}\left(10^{-4}\right)$ & -7.9229 & -29.6 & -33.7 & -21.7 & -36.5 \\
$e_{2}\left(10^{-4}\right)$ & 14.3 & 23.3 & 16.2 & -76.2 & -95.2 \\
$e_{3}\left(10^{-5}\right)$ & 8.99993 & 8.93084 & 10.3683 & 1.52558 & -2.25792 \\
$e_{4}\left(10^{-7}\right)$ & -2.62981 & -9.41432 & -11.1793 & -0.344321 & 12.6612 \\
$e_{5}$ & 0.05731 & -0.17619 & -0.2807 & -0.46179 & -0.33204 \\
$f_{1}\left(10^{-9}\right)$ & 0.541421 & 1.93193 & 3.15653 & -3.019 & -8.38 \\
$f_{2}$ & -0.00115 & -0.00086716 & 0.00016157 & 0.00572 & 0.00507 \\
\hline & & & & &
\end{tabular}

(b)

\begin{tabular}{ccccc}
\hline$\eta^{*}$ & 0.025 & 0.01 & 0.005 & 0 \\
\hline$a_{1}$ & 3.35806 & -1.23867 & -0.45996 & 3.37529 \\
$b_{1}$ & -0.55164 & -0.16511 & -0.15958 & -0.47228 \\
$b_{2}$ & -21.84517 & -21.43617 & -19.51907 & -16.87839 \\
$b_{3}$ & 0.48118 & 0.50196 & 0.36419 & 0.23426 \\
$c_{1}$ & 0.0089 & -0.00076226 & -0.00112 & 0.00769 \\
$c_{2}$ & 33.88561 & 37.06971 & 26.23782 & 28.47907 \\
$c_{3}$ & -0.00646 & -0.00617 & -0.00152 & -0.00163 \\
$c_{4}$ & 0.50334 & 0.41875 & 0.27709 & 0.11241 \\
$c_{5}$ & -0.91887 & -0.69871 & -0.00369 & 0.39874 \\
$c_{6}$ & -0.00177 & -0.00627 & -0.0066 & 0.00219
\end{tabular}




\begin{tabular}{ccccc}
$d_{1}$ & 0.01021 & 0.00696 & -0.0019 & -0.00585 \\
$d_{2}\left(10^{-5}\right)$ & 14.0824 & 10.4465 & -4.69792 & -2.77141 \\
$d_{3}\left(10^{-5}\right)$ & -19.7824 & 2.52789 & 19.2577 & -4.81271 \\
$d_{4}$ & 0.82951 & 0.59685 & -0.16027 & -0.11331 \\
$d_{5}$ & 0.0039 & 0.00071557 & -0.01186 & -0.02378 \\
$d_{6}$ & -30.59648 & -32.28237 & -20.44928 & -36.42157 \\
$d_{7}\left(10^{-5}\right)$ & -4.88882 & 2.41696 & 2.25951 & -5.4103 \\
$e_{1}\left(10^{-4}\right)$ & -68.1 & -81.3 & 25.1 & 109.8 \\
$e_{2}\left(10^{-4}\right)$ & -97.5 & -19.9 & 94.8 & -39.1 \\
$e_{3}\left(10^{-5}\right)$ & -7.27793 & -3.77109 & 12.6135 & 32.7194 \\
$e_{4}\left(10^{-7}\right)$ & 19.4994 & -4.12378 & -20.9783 & 4.26801 \\
$e_{5}$ & -0.19899 & -0.12045 & 0.16124 & 0.23735 \\
$f_{1}\left(10^{-9}\right)$ & -10.5367 & -2.52886 & 13.0079 & 2.20107 \\
$f_{2}$ & 0.00356 & -0.00183 & -0.00901 & 0.00409 \\
\hline
\end{tabular}

\section{Parametric study}

\subsection{Variation of tunnel strain with different critical softening parameters}

Values of $\varepsilon_{\theta}$ are calculated by the proposed regression model, which are plotted for Cases A1 to A9 versus GSI ${ }^{p}, \sigma_{0}$, and $p_{\mathrm{i}} / \sigma_{0}$, respectively, as in Figs. 9 and 10 . In Fig. 9 , GSI ${ }^{\mathrm{p}}$ is variable, $\sigma_{0}$ is $30 \mathrm{MPa}$ and $p_{\mathrm{i}} / \sigma_{0}$ is 0.1 , and in Fig. $10, p_{\mathrm{i}} / \sigma_{0}$ is variable, $\mathrm{GSI}^{\mathrm{p}}$ is 30 and $\sigma_{0}$ is $5 \mathrm{MPa}$. When $\mathrm{GSI}^{\mathrm{p}}$ is 70 or 75 , and $p_{\mathrm{i}} / \sigma_{0}$ is $0.3, \varepsilon_{\theta}$ maintains constant. The reason is that $\mathrm{GSI}^{\mathrm{p}}$ and $p_{\mathrm{i}} / \sigma_{0}$ are relatively large, so that the rock mass takes elastic deformations and is independent of $\eta^{*}$. With plastic deformations in the rock mass, $\varepsilon_{\theta}$ decreases to a substantial constant with the increase in $\eta^{*}$. The decrease of $\varepsilon_{\theta}$ is induced by the shrinkage of the plastic residual area. If $\eta^{*}$ is nil, all rock mass within the plastic area is characterised with the residual strength; and the maximum $\varepsilon_{\theta}$ is therefore reached; as $\eta^{*}$ increases, $\varepsilon_{\theta}$ falls rapidly since the softening area expands; and $\varepsilon_{\theta}$ becomes stable when the softening zone dominates in the plastic area. The expansion of the plastic residual area is the critical factor enhancing the deformation within the rock mass. In the practical engineering, the measures to 
decrease the plastic residual zone can substantially improve the tunnel stability. Furthermore, $\varepsilon_{\theta}$ falls quickly and becomes constant within a small $\eta^{*}$ for excellent quality rock mass, whereas $\varepsilon_{\theta}$ for the weak rock mass decreases slowly and the decline process is prolonged until a plateau is reached (see Fig. 10). Hence, the rock mass deformation decreases more suddenly with a better quality rock while $\eta^{*}$ increases.

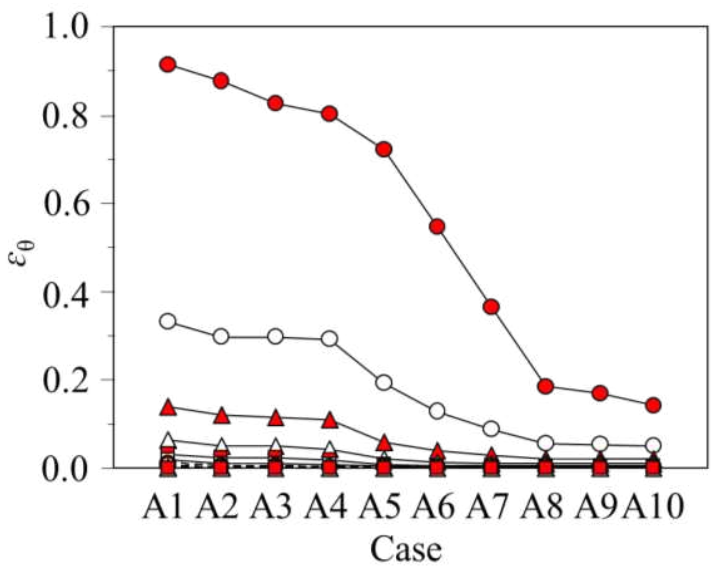

(a)

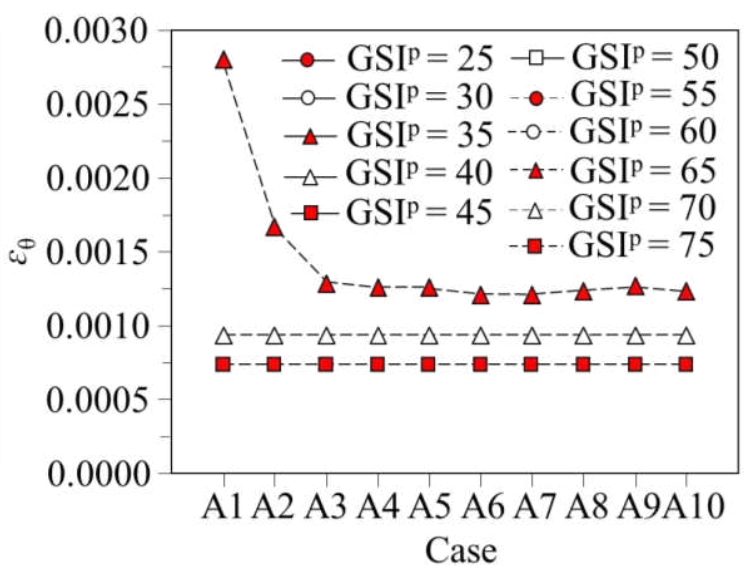

(b)

Fig. 9 Variation of $\varepsilon_{\theta}$ versus cases A1 to A9: (a) GSI ranges from 25 to 75 ; (b) GSI ${ }^{\mathrm{p}}=65,70,75$

\subsection{Difference of tunnel strain between the EPP and EBP rock masses}

$\varepsilon_{\theta}$ for the EPP rock mass is symbolised by $\varepsilon_{\theta_{-} E P P .}$ The increase ratio of $\varepsilon_{\theta}$ for the

EBP rock mass in comparison to the EPP counterpart is denoted by $\Delta \varepsilon_{\theta} / \varepsilon_{\theta_{-}}$EPP.

$\Delta \varepsilon_{\theta} / \varepsilon_{\theta_{-} \text {EPP versus GSI }}$ for variations in $\sigma_{0}$ and $p_{\mathrm{i}} / \sigma_{0}$ is plotted in Fig. 11.
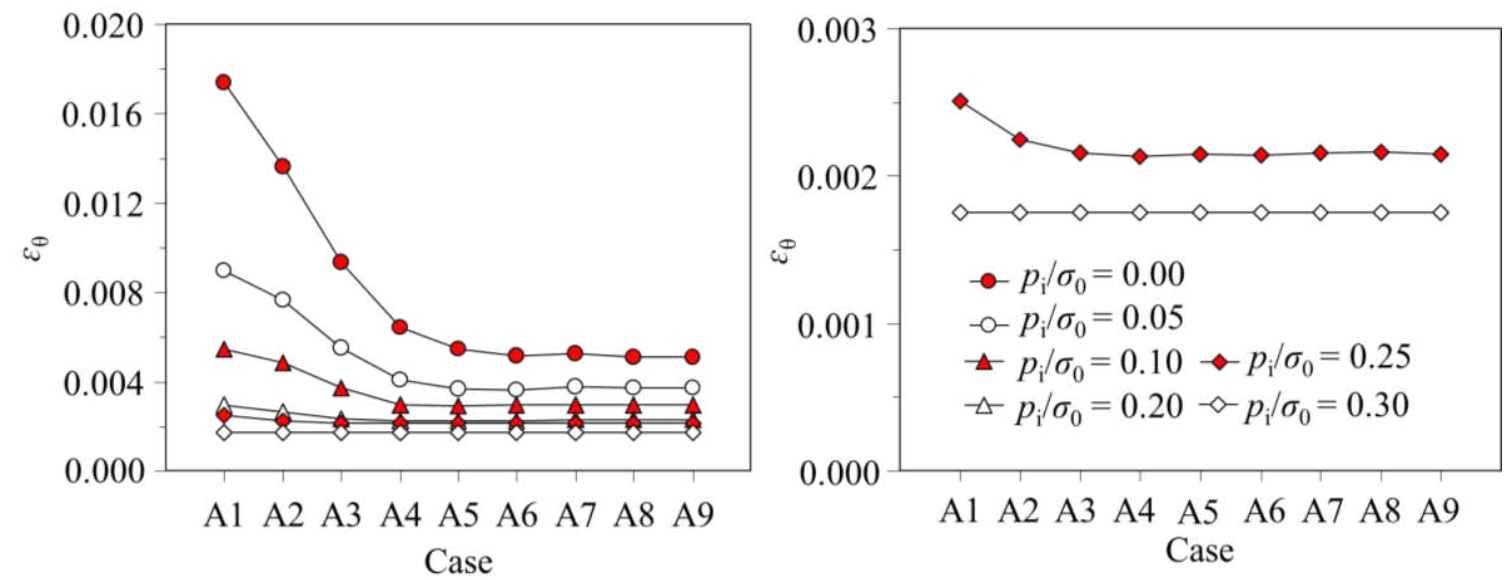

Fig.10 Variation of $\varepsilon_{\theta}$ versus cases A1 to A9: (a) $p_{\mathrm{i}} / \sigma_{0}$ ranges from 0 to 0.3 ; (b) $\sigma_{0}=0,0.05$; (c) $\sigma_{0}$ $=0.1,0.2 ;$ (d) $\sigma_{0}=0.25,0.3$ 


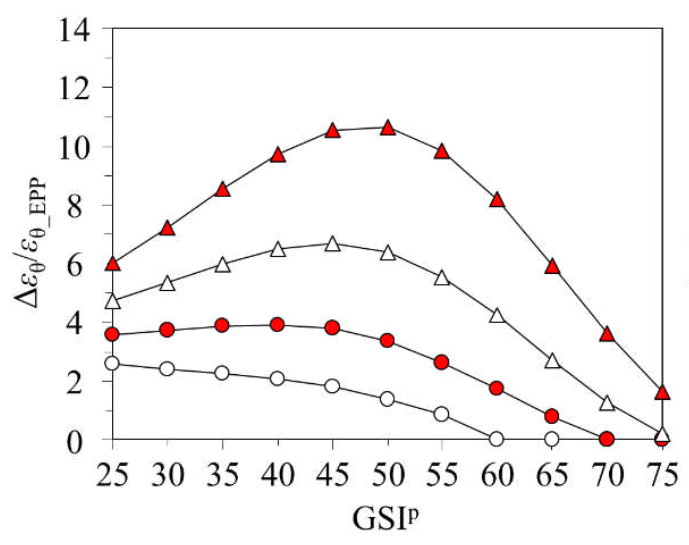

(a)

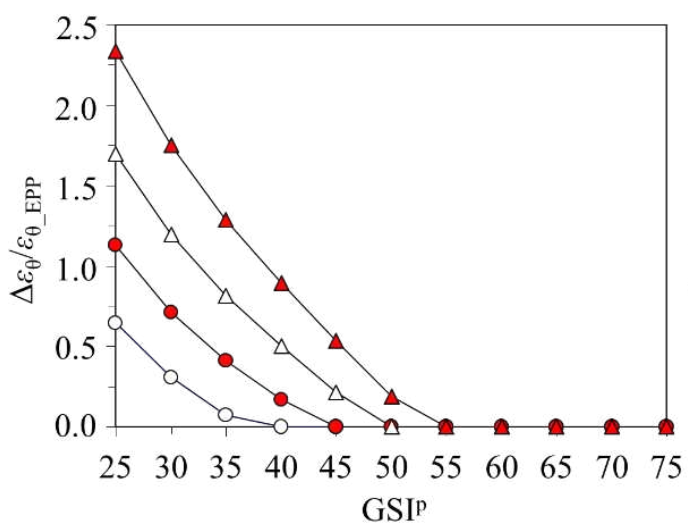

(c)

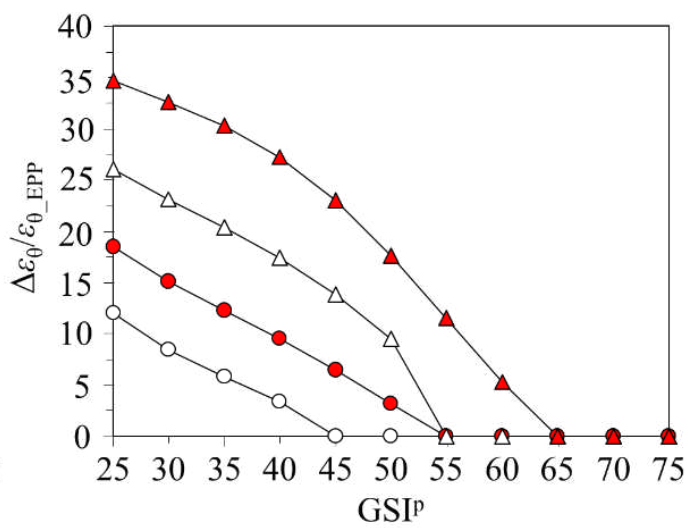

(b)

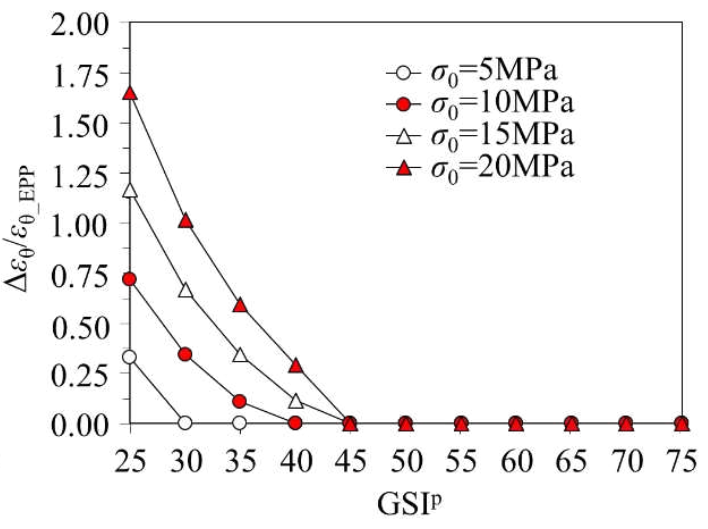

(d)

Fig. 11 Variation of $\Delta \varepsilon_{\theta} / \varepsilon_{\theta}$ EPP versus GSI ${ }^{\mathrm{p}}$ : (a) $p_{\mathrm{i}} / \sigma_{0}=0$; (b) $p_{\mathrm{i}} / \sigma_{0}=0.1$; (c) $p_{\mathrm{i}} / \sigma_{0}=0.2$; (d)

$$
p_{\mathrm{i}} / \sigma_{0}=0.3
$$

When $p_{\mathrm{i}} / \sigma_{0}$ is $0.1,0.2$ and $0.3, \Delta \varepsilon_{\theta} / \varepsilon_{\theta}$ EPP decreases as $\mathrm{GSI}^{\mathrm{p}}$ increases (see Fig. 11(b) - (d)). Hence, while $p_{\mathrm{i}} / \sigma_{0}$ exceeds 0.1 , the effect of $\eta^{*}$ on $\varepsilon \theta$ for the weakest rock mass $\left(\mathrm{GSI}^{\mathrm{p}}=25\right)$ is the greatest, which should be highlighted. While $p_{\mathrm{i}}$ is 0 , and $\sigma_{0}$ ranges from $10 \mathrm{MPa}$ to $20 \mathrm{MPa}, \Delta \varepsilon_{\theta} / \varepsilon_{\theta_{-}}$EPP rises but then decreases with the increase in GSI ${ }^{\mathrm{p}}$ (Fig. 11(a)). The maximum $\Delta \varepsilon_{\theta} / \varepsilon_{\theta_{-}}$EPP appears while GSI ${ }^{\mathrm{p}}$ is around 45 or 50 . In this case, the influence of $\eta^{*}$ on $\varepsilon_{\theta}$ for the moderate rock mass $\left(\mathrm{GSI}^{\mathrm{p}}=\right.$ $45,50)$ is the largest. For GSI ${ }^{\mathrm{p}}$ is 50 and $\sigma_{0}$ is $20 \mathrm{MPa}, \Delta \varepsilon_{\theta} / \varepsilon_{\theta_{-} \text {EPP }}$ reaches almost 10.64 for $p_{\mathrm{i}} / \sigma_{0}$ is 0 but drops to 1.77 for $p_{\mathrm{i}} / \sigma_{0}$ is 0.1 (see Fig. 11(a) - (b)). This means that the growth of $p_{\mathrm{i}}$ effectively weakens the softening effect on the deformation for 
moderate quality rock mass with high initial stress. Furthermore, when GSI ${ }^{p}$ is greater than 55 and $p_{\mathrm{i}} / \sigma_{0}$ exceeds $0.1, \Delta \varepsilon_{\theta} / \varepsilon_{\theta_{-}}$EPP for most cases is 0 , which means $\varepsilon_{\theta}$ by EPP and EBP rock masses are equivalent (see Fig. 11(b) - (d)). This is because that the rock mass undergoes an elastic deformation. Therefore, if $p_{\mathrm{i}} / \sigma_{0}$ reaches 0.1 , the rock mass deformation is inconsiderable and irrespective of $\eta^{*}$ for the excellent rock mass quality $\left(\mathrm{GSI}^{\mathrm{p}} \geq 55\right)$.

\subsection{Sensitive analysis}

Table 13 GSI, $\sigma_{0}$ and $p_{\mathrm{i}} / \sigma_{0}$ for cases B1 to B3

\begin{tabular}{cccc}
\hline & Case B1 & Case B2 & Case B3 \\
\hline GSI $^{\mathrm{p}}$ & 70 & 50 & 30 \\
$\sigma_{0}(\mathrm{MPa})$ & 20 & 20 & 20 \\
$p_{\mathrm{i}} / \sigma_{0}$ & 0.15 & 0.15 & 0.15 \\
\hline
\end{tabular}

Figure 12 illustrates the sensitivity analysis concerning the tunnel strain $\varepsilon \theta$, showing the relative significance of the most significant input data (i.e. $\mathrm{GSI}^{\mathrm{p}}, \sigma_{0}$ and $p_{\mathrm{i}} / \sigma_{0}$ ) on this final output (i.e. $\varepsilon_{\theta}$ ). Three base cases with different rock mass qualities are given in Table 13. In the sensitive analysis, $\sigma_{0}$ varies between $5 \mathrm{MPa}$ and $30 \mathrm{MPa}$ with even intervals of $5 \mathrm{MPa} . p_{\mathrm{i}} / \sigma_{0}$ ranges from 0 to 0.225 with 0.025 intervals. GSI ranges from 25 to 75 with 5 intervals. $\mathrm{GSI}^{\mathrm{p}}, \sigma_{0}$ or $p_{\mathrm{i}} / \sigma_{0}$ is represented by the variable $m$. GSI ${ }^{\mathrm{p}}, \sigma_{0}$ or $p_{\mathrm{i}} / \sigma_{0}$ in cases $\mathrm{B} 1$ to $\mathrm{B} 3$ is represented by $m_{\text {base. }} \quad \varepsilon_{\theta}$ calculated by cases $\mathrm{B} 1$ to $\mathrm{B} 3$ is represented by $\varepsilon_{\theta, \text { base. }}$

In comparison with the EBP rock mass, $\varepsilon_{\theta} / \varepsilon_{\theta}$,base of the EPP rock mass with the moderate and weak rock qualities tends to be closer to the line for $\varepsilon_{\theta} / \varepsilon_{\theta \text {,base }}$ is 1 (see Fig. 12(b) - (c)). In this respect, $\varepsilon_{\theta}$ for the EBP rock mass is more sensitive to the change in $\mathrm{GSI}^{\mathrm{p}}, p_{\mathrm{i}} / \sigma_{0}$ and $\sigma_{0}$. However, for the excellent quality rock mass, $\varepsilon_{\theta} / \varepsilon_{\theta}$,base of EBP rock mass coincides with that of EPP rock mass (Fig. 12(a)). This is 
attributed to that the rock mass exhibits the elastic behaviour, and thus $\varepsilon_{\theta}$ is independent of the plastic parameters. In this respect, the influence of $\mathrm{GSI}^{\mathrm{p}}, p_{\mathrm{i}} / \sigma_{0}$ or $\sigma_{0}$ on $\varepsilon_{\theta}$ by EPP and EBP rock masses are equivalent.

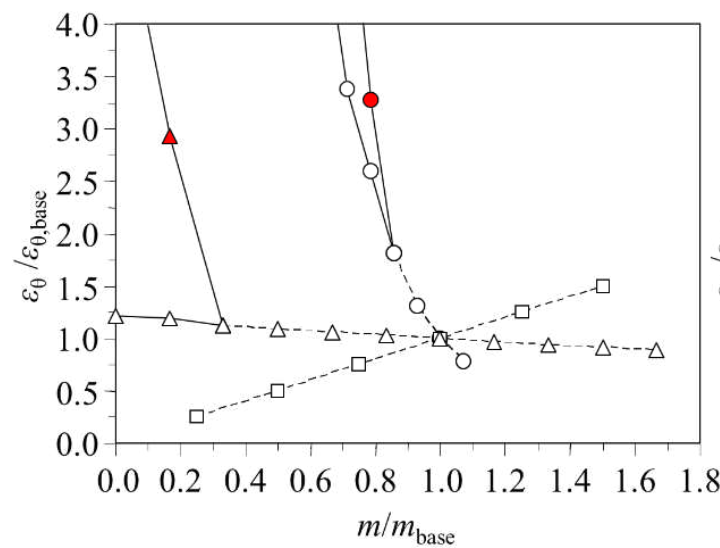

(a)

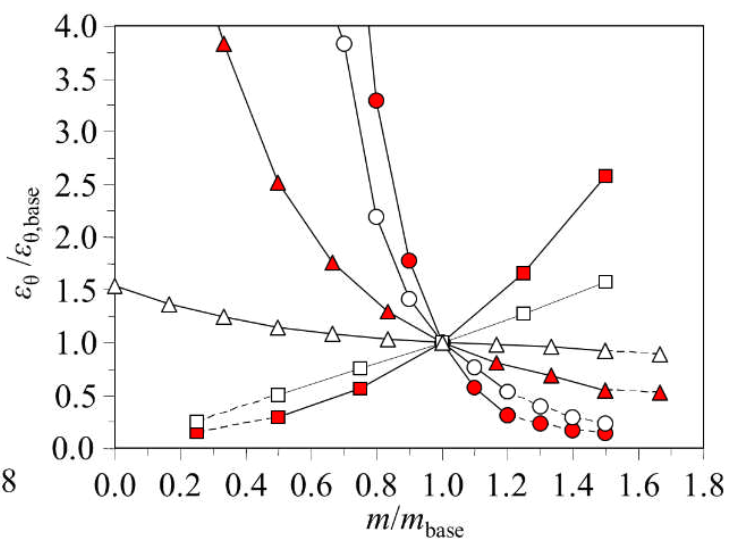

(b)

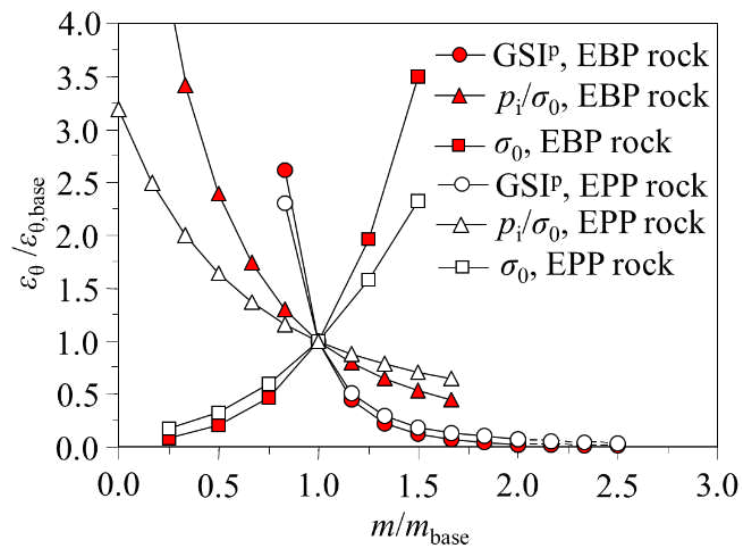

(c)

Fig. 12 Sensitive analysis of GSI ${ }^{\mathrm{p}}, \sigma_{0}$ and $p_{\mathrm{i}} / \sigma_{0}$ on $\varepsilon_{\theta}$ : (a) cases B1; (b) case B2; (c) case B3

Among the input parameters $\mathrm{GSI}^{\mathrm{p}}, \sigma_{0}$ and $p_{\mathrm{i}} / \sigma_{0}$, the change in $\mathrm{GSI}^{\mathrm{p}}$ gives rise to the greatest change in $\varepsilon_{\theta}$. Especially for the excellent rock mass, $\varepsilon_{\theta} / \varepsilon_{\theta \text {,base }}$ by GSI ${ }^{\mathrm{p}}$ is considerably higher than $\sigma_{0}$ and $p_{\mathrm{i}} / \sigma_{0}$ (Fig. 12(a)). Therefore, GSI ${ }^{\mathrm{p}}$ is of vital importance in controlling $\varepsilon_{\theta}$. The relative significance of $p_{\mathrm{i}} / \sigma_{0}$ and $\sigma_{0}$ varies with different conditions. For the EBP rock mass, when $p_{\mathrm{i}} / \sigma_{0}$ decreases and $\sigma_{0}$ increases with an equivalent variation, $\varepsilon_{\theta} / \varepsilon_{\theta}$,base affected by $p_{\mathrm{i}} / \sigma_{0}$ is always higher than that by $\sigma_{0}$; and it becomes remarkably higher while $p_{\mathrm{i}} / \sigma_{0}$ decreases to a small value. Hence, for 
the EBP rock mass, when $p_{\mathrm{i}} / \sigma_{0}$ decreases and $\sigma_{0}$ increases, the influence of $p_{\mathrm{i}} / \sigma_{0}$ on $\varepsilon \theta$ is larger than that of $\sigma_{0}$. For all the other conditions, the influence of $\sigma_{0}$ on $\varepsilon_{\theta}$ is greater than that of $p_{\mathrm{i}} / \sigma_{0}$. For instance, for the EPP rock mass, the change in $\sigma_{0}$ causes a larger variation in $\varepsilon_{\theta}$; for the EBP rock mass, when $p_{\mathrm{i}} / \sigma_{0}$ increases and $\sigma_{0}$ decreases with the equivalent variation, a decrease of $\sigma_{0}$ yields a higher reduction of $\varepsilon_{\theta}$. As the weak rock mass shows the EPP behaviour (Hoek and Brown, 1997), the reduction of $\sigma_{0}$ exerts greater influence than the increase in $p_{\mathrm{i}} / \sigma_{0}$ in controlling the rock deformation for the weak rock mass. In the tunnelling engineering, the reduction of $\sigma_{0}$ and the increase of $p_{\mathrm{i}} / \sigma_{0}$ can be obtained by relieving the stress and installing the rigid support, respectively.

\section{Conclusions}

Various GSI were considered to quantify the input geological parameters for the strain-softening rock masses with various qualities. A specialised numerical scheme was presented to calculate the tunnel strain around a circular opening within the rock mass. The proposed numerical procedure and the input geological parameters were validated through comparison of the tunnel strain obtained by the numerical procedure with that predicted by the previous studies. With the obtained input geological parameters, more accurate quantification of the tunnel strain was obtained by an iterative numerical procedure. A regression model, composed of 12 fitting equations, was further proposed: 3 equations were to calculate the critical tunnel strain, the critical support pressure and the tunnel strain with elastic behaviour, and 9 equations were for the tunnel strain with different strain-softening behaviours. The model 
provides practical guidelines to assess the deformations of the rock mass prior to the tunnel construction. Following conclusions can then be drawn:

The tunnel strain wanes to a constant value with the critical softening parameter keeps increasing, which is mainly ascribed to the shrinkage of the plastic residual area. Reversely, the rock deformation is mainly raised due to the expansion of the plastic residual area. In the practical engineering, the measures to decrease the plastic residual area can substantially improve the tunnel stability.

While the support pressure exceeds a certain value $\left(p_{\mathrm{i}} / \sigma_{0} \geq 0.1\right)$, the critical softening parameter makes the most significant influence on the tunnel strain for the weakest rock mass $\left(\mathrm{GSI}^{\mathrm{p}}=25\right)$. In comparison, with no support pressure $\left(p_{\mathrm{i}} / \sigma_{0} \geq 0\right)$ and relatively high initial stress $\left(\sigma_{0} \geq 10 \mathrm{MPa}\right)$, the influence of the critical softening parameter for the moderate rock mass ( $\mathrm{GSI}^{\mathrm{p}}$ is around 45 or 50 ) is the most significant. While the support pressure that acted on the good rock mass quality (GSI $\geq 55$ ) exceeds a certain value, the rock mass deformation becomes inconsiderable.

While the rock mass exhibits a strain-softening behaviour, the tunnel strain for the EBP rock mass can be affected by the change in the rock mass quality, the support pressure and the initial stress state. Among the three input geological parameters (i.e. $\mathrm{GSI}^{p}$, the support pressure, and the initial stress), GSI ${ }^{p}$ is of vital importance in controlling the tunnel strain. The relative significance of the support pressure and initial stress varies with different conditions. For the EBP rock mass, with the support pressure decreases and the initial stress increases, the tunnel strain is mostly influenced by the variation in the support pressure. For all other conditions, the 
initial stress state becomes the critical factor.

\section{Acknowledgement}

The authors acknowledge the financial support provided by the National Science Foundation of China (Grant No. 52009129 and 51909248). 


\section{References}

Alonso, E., Alejano, L.R., Varas, F., Fdez-Manin, G., Carranza-Torres, C., 2003. Ground response curves for rock masses exhibiting strain-softening behaviour. Int. J. Rock Mech. Min. Sci. Geomech. Abstr. 27, 1153-1185.

Asef, M.R., Reddish, D.J., Lloyd, P.W., 2000. Rock-support interaction analysis based on numerical modelling. Geotech. Geol. Eng. 18(1), 23-37.

Aydan, O., Dalgic, S., 1998. Prediction of deformation behaviour of 3-lanes Bolu tunnels through squeezing rocks of North Anatolian fault zone (NAFZ). In: Proceedings of the Regional Symposium on Sedimentary Rock Engineering, Taipei, Taiwan, 20-22, November 1998. Public Construction Comission of Taiwan.

Brown, E.T., Bray, J.W., Ladanyi, B., Hoek, E., 1983. Ground response curves for rock tunnels. J. Eng. Mech. ASCE. 109, 15-39.

Barton, N., Lien, R., Lunde, J., 1974. Engineering classification of rock masses for the design of tunnel support. Rock Mech. 6(4), 189-236.

Barton, N., 1987. Rock mass classification, tunnel reinforcement selection using the Q-system. In: Proceedings of the ASTM Symposium on Rock Classification Systems for Engineering Purposes. Cincinnati, Ohio.

Barton, N., 2002. Some new Q-value correlations to assist in site characterisation and tunnel design. Int. J. Rock Mech. Min. Sci. 39, 185-216.

Bieniawski, Z.T., 1978. Determination rock mass deformability: experience from case histories. Int. J. Rock Mech. Min. Sci. Geomech. Abstr. 15, 237-247.

Bieniawski, Z.T., 1984. Rock Mechanics Design in Mining and Tunnelling. A. A. Balkema, Rotterdam, pp. 97-133.

Bieniawski, Z.T., 1989. Engineering Rock Mass Classifications. John Wiley and Sons, New York.

Basarir, H., 2008. Analysis of rock-support interaction using numerical and multiple regression modelling. Can. Geotech. J. 45,1-13

Basarir, H., Genis, M., Ozarslan, A., 2010. The analysis of radial displacements occurring near the face of a circular opening in weak rock mass. Int. J. Rock Mech. Min. Sci. 47, 771-783.

Cai, M., Kaiser, P.K., Tasaka Y., Minami M., 2007. Determination of residual strength parameters of jointed rock mass using the GSI system. Int. J. Rock Mech. Min. Sci. 44, 247-265.

Carranze-Torres, C., Fairhurst, C., 2000. Application of the convergence-confinement method of tunnel design to rock masses that satisfy the Hoek-Brown failure criterion. Tunn. Undergr. Space Technol. 15(2), 187-213.

Duncan, Fama, M.E., Trueman, R., Craig, M.S., 1995. Two and three dimensional elastoplastic analysis for coal pillar design and its application to highwall-mining. Int. J. Rock Mech. Sci. Geom. Abstr., $32(3), 215-225$.

Einstein, H.H., Schwartz, C.W., 1980. Discussion of the article: simplified analysis for tunnel supports. J. Geotech. Eng. Div. ASCE. 106(7), 835-838.

Ewy, R.T., Cook, N.G.W., 1990. Deformation and fracture around cylindrical openings in rock - I. Observations and analysis of deformations, Int. J. Rock Mech. Min. Sci. Abstr. 27(5), 387-407.

Goh, A.T.C., Zhang, W.G., 2012. Reliability assessment of stability of underground rock caverns. Int. J. Rock Mech. Min. Sci. 55, 157-163.

Hudson, J.A., Harrison, J.P., 2000. Engineering rock mechanics - an introduction to the principles. 
London: Elsevier.

Hoek, E., Marinos, P., 2007. A brief history of the development of the Hoek-Brown failure criterion. Soils Rocks. 30 (2), 85-92.

Hoek, E., Carranza-Torres, C., Corkum, B., 2002. Hoek-Brown criterion-2002 edition. Proc NARMS-TAC Conference, Toronto, 1, 267-273.

Hoek, E., 1998. Tunnel support in weak rock. In: Symposium of Sedimentary rock Engineering, Taipei, Taiwan, pp. 20-22.

Hoek, E., 2012. Blast damage factor D. Technical note for RocNews-February 2, 2012, Winter 2012 Issue.

Hoek, E., Brown, E.T., 1997. Practical estimates of rock mass strength. Int. J. Rock Mech. Min. Sci. 34(8), 1165-1186.

Hoek, E., Marinos, P., 2000. Predicting tunnel squeezing problems in weak heterogeneous rock masses. Tunnels and Tunnelling International. 32(11), 45-51; 32(12), 34-36.

Hoek, E., Diederichs, M.S., 2006. Empirical estimation of rock mass modulus. Int. J. Rock Mech. Min. Sci. 43, 203-215.

Hoek, E., Brown, E.T., 1980. Underground excavations in rock. Institution of Mining and Metallurgy, London, UK.

Hoek, E., 1994. Strength of rock and rock masses. ISRM News Journal, 2(2), 4-16.

Hoek, E., Kaiser, P.K., Bawden, W.F., 1995. Support of underground excavations in hard rock. Rotterdam: Balkema.

Kalamaris, G.S., Bieniawski, Z.T., 1995. A rock mass strength concept for coal incorporating the effect of time. In Proceedings of the 8th International Congress on Rock Mechanics. A.A. Balkema, Rotterdam, The Netherlands, Vol. 1, pp. 295-302.

Lee, Y.K., Pietruszczak, S., 2008, A new numerical procedure for elasto-plastic analysis of a circular opening excavated in a strain-softening rock mass. Tunn. Undergr. Space Technol. 15(2), 187-213.

Marinos, V., Marinos, P., Hoek, E., 2006. The geological Strength index: applications and limitations. Bull. Eng. Geol. Env., 65(2), 129-142.

Nawrocki, P.A., Dusseault, M.B., 1995. Modelling of damaged zone around openings using radius-dependent Young’s modulus, Rock Mech. Rock Eng. 28(4): 227-239.

Read, S.A.L., Richards, L.R. and Perrin, N.D., 1999. Application of the Hoek-Brown failure criterion to New Zealand greywacke rocks. In: Proceeding of the 9th International Congress on Rock Mechanics. Paris, France, 25-28 August 1999, A.A. Balkema, Rotterdam, The Netherlands, pp, 655-660

Ramamurthy, T. 1986. Stability of rock masses. Indian Geomechanics Journal. 16(1) pp, 1-74.

Sari, D., 2007. Rock mass response model for circular openings. Can. Geotech. J. 44, 891-904.

Sheorey, P.R., 1997. Empirical rock failure criteria. A.A. Balkema, Rotterdam, The Netherlands, pp. 176.

Serafim, J.L., Pereira, J.P., 1983. Considerations of the geomechanics classification of Bieniawski. Proceedings of the international Symposium on Engineering Geology and Underground Construction 1. A.A. Balkema, Rotterdam, The Netherlands, pp. 1133-1142.

Sjoberg, Jonny, 1997. Estimating rock mass strength using the Hoek-Brown failure criterion and rock mass classification-a review and application to the Aznalcollar pit. Technical Report 1997: Lulea University of Technology.

Sharan, S.K., 2005. Exact and approximate solutions for displacements around circular openings in 
elasto-brittle-plastic Hoek-Brown rock. Int. J. Rock Mech. Min. Sci. 42, 542-549

Trueman, R., 1988. An evaluation of strata support techniques in dual life gateroads. (Ph.D. thesis). University of Wales, Cardiff, UK.

Wang, S.L., Yin, X.T., Tang, H., Ge, X.R., A new approach for analyzing circular tunnel in strain-softening rock masses. Int. J. Rock Mech. Min. Sci. 47, 170-178.

Wilson, A.H., 1980. A method of estimating the closure and strength of lining required in drivages surrounded by a yield zone. International Journal of Rock Mechanics, Mining Sciences and Geomechanics Abstracts, 1980, 17: 349-355. Int. J. Rock Mech. Min. Sci. 47, 170-178.

Yudhbir, R.K., Lemanza, W., Prinzl, F., 1983. An empirical failure criterion for rock masses. In: Proceedings of the 5th International Congress on Rock Mechanics. A.A. Balkema, Rotterdam, The Netherlands, Vol. 1, B1-B8.

Zhang, W.G., Goh, A.T.C., 2015. Regression models for estimating ultimate and serviceability limit states of underground rock caverns. Eng. Geol. 188, 68-76.

Zhu, W.S., Sui, B., Li, X.J., Li, S.C., Wang, W.T., 2008. A methodology for studying the high wall displacement of large scale underground cavern complexes and its applications. Tunn. Undergr. Space Technol. 23, 651-664.

Zhang, Q., Jiang, B.S., Wang, S.L., Ge, X.R., Zhang, H.Q., 2012. Elasto-plastic analysis of a circular opening in strain-softening rock mass. Int. J. Rock Mech. Min. Sci. 50, 38-46.

Zhang Q, Jiang B.S., Wu, X.S., Zhang, H.Q., Han, L.J., 2012. Elasto-plastic coupling analysis of circular openings in elasto-brittle-plastic rock mass. Theoretical and Applied Fracture Mechanics, $60,60-67$. 